\title{
Direct impacts of different types of El Niño in developing summer on East Asian precipitation
}

\author{
Na WEN ${ }^{1}$, Laurent Li $^{2}$, Jing-Jia Luo ${ }^{1}$,
}

1. Key Laboratory of Meteorological Disaster of Ministry of Education/Collaborative Innovation Center on Forecast and Evaluation of Meteorological Disasters/Institute for Climate and Application Research (ICAR), Nanjing University of Information Science and Technology, Nanjing, China

2. Laboratoire de Météorologie Dynamique, CNRS, Sorbonne Université, Ecole Normale Supérieure, Ecole Polytechnique, Paris, France

Climate Dynamics, accepted manuscript

Corresponding author address:

Dr. Na Wen, College of Atmospheric Sciences, Nanjing University of Information Science \& Technology, Nanjing 210044, China, E-mail: wenna@nuist.edu.cn 
Abstract: This study revisits the impacts of different types of El Niño on East Asian summer precipitation (EASP) with observed and re-analyzed data from 1958 to 2015. It focuses on the boreal summer preceding peaks of El Niño when prominent SST anomalies are mainly situated in the tropical Pacific. Distinct responses of EASP are obtained for the three identified types of SST anomalies noted as summer EP (Eastern Pacific) El Niño, summer MP (Mixed-type Pacific) El Niño, and summer CP (Central Pacific) El Niño. In the case of summer EP El Niño, there is a robust south-north rainfall dipole with anomalous dry conditions in North China and wet conditions in Southeast China. Such a rainfall pattern is mainly attributed to a low-pressure anomaly over Northeast Asia. For summer MP El Niño, it presents a tripolar pattern of precipitation anomalies with wetness along the Yangtze-Huaihe River valley and dryness in both South and North China. This is due to the presence of low-pressure anomalies over Northeast China and a westward shift of the Western Pacific Subtropical High. Summer CP El Niño shows a triangle-pattern of precipitation anomalies with wet conditions in both southern and northern China, but dry conditions in the Jianghuai region (north of the Yangtze River in East China), caused by low-pressure anomalies over central-north China.

Further study investigates how different types of summer El Niño induce different changes of the Walker circulation and associated large-scale convergence/divergence outside the tropics, and ultimately provoke different responses of atmospheric circulation. For summer EP El Niño, tropical perturbations over the east-central tropical Pacific and over North India can enter into the subtropical jet and make a mid-latitude low pressure belt response at upper levels of the atmosphere. For summer MP El Niño, the perturbation over the east-central tropical Pacific seems ineffective in transmitting atmospheric anomalies to mid-latitudes. As a result, they are mainly confined to the tropics and lead to a general rise of the upper-level geopotential height over the entire tropics. However, the perturbation over Northwest Africa can excite northeastward propagating Rossby waves in mid-high latitudes. For summer CP El Niño, the induced fluctuant wave train within the subtropical jet is likely the competing effect of perturbations over the east-central tropical Pacific, North India and North Africa. Furthermore, for all the three types of summer El Niño, perturbations can trigger a similar low-level meridional wave train along the East Asian coast through the monsoon trough. However, a slight westward shift of the wave train makes a sensitive impact on EASP.

Key words: Different Types of El Niño, East Asian Summer Precipitation, El Niño developing stage 


\section{Introduction}

El Niño ${ }^{1}$ is the most prominent phenomenon of year-to-year climate variability on Earth. It exerts strong impacts on climate variation at both regional and global scales (Ropelewski and Halpert, 1987; Thenberth et al., 1998), and therefore provides a major source of predictability for climate in regions even far from the tropical Pacific. However, the role of El Niño in forecasting summer precipitation in China is weakened in recent decades (Gao and Wang, 2007; Zong et al., 2010), which is probably due to the frequent occurrence of a new type of El Niño since the late 1990s (Yeh et al., 2009; Pascolini-Campbell et al., 2014). Different from the conventional El Niño which is characterized by a major warming in the eastern Pacific (so called eastern Pacific or EP El Niño), the maximum SST anomaly of this new type of El Niño is mainly located in the central equatorial Pacific. Hence it is termed by different authors as the dateline El Niño (Larkin and Harrison, 2005), El Niño Modoki (Ashok et al., 2007), central Pacific (CP) El Niño (Kao and Yu, 2009), and warm-pool El Niño (Kug et al., 2009). The westward displacement of tropical heating along the equatorial Pacific has a large potential to modify the tropical-midlatitude atmospheric teleconnection (Alexander et al., 2002; Barsugli and Sardeshmukh, 2006), resulting in different impacts on weather and climate all over the world (Larkin and Harrison, 2005; Kumar et al., 2006; Weng et al. 2007, 2009; Chen and Tam, 2010; Graf and Zanchettin, 2012; Song et al, 2011).

Although our understanding of the impacts of different types of El Niño on the East Asian climate has largely been improved (Weng et al., 2007, 2009; Feng et al., 2011, 2016; Feng and Li, 2011; Yuan and Song, 2012; Zhang et al., 2011; Yuan et al., 2019), there are still many controversies for this issue, especially for the impact of El Niño during its developing summer. For instance, Weng et al. (2007) suggested that, in boreal summer, El Niño Modoki could induce rainfall deficiencies in the lower reaches of the Yangtze River valley and the far northern part of northeast China, but excessive rainfall in southern China due to weakening of the East Asian summer monsoon. Feng et al. (2016) found a similar distribution of precipitation anomalies for CP El Niño in association with an anomalous cyclonic circulation over the western Pacific. They also noted that, during its developing summer, the conventional El Niño has limited impact on the East Asian summer precipitation (EASP). With a partial regression on boreal winter El Niño indices, Yuan and Song (2012) also found different signatures of EASP between CP El Niño and the conventional El Niño. However, their response of EASP to CP El Niño, with dry conditions over southeastern China and wet conditions over parts of Northeast China, was nearly opposite to what shown in Feng et al. (2016) and Weng et al. (2009).

The disagreement among previous works for the issue of different types of El Niño can be explained with three factors. Firstly, due to the complex evolution of El Niño, the precise type of El Niño classified by the winter El Niño indices may not correctly represent its actual state in summer. For example, the 2009/10 El Niño is one of the strongest CP events on record in winter, but the maximum SST anomaly

\footnotetext{
${ }^{1}$ In this paper, unless otherwise specified, El Niño refers to both the warm and cold phase of El Nino - Southern Oscillation.
} 
during its developing summer actually occurred in the eastern equatorial Pacific. Since the response of the atmosphere to the underlying SST forcing is rapid (within a few weeks) (e.g., Gill 1980; Hoskins and Karoly 1981; Li and Conil 2003; Liu and Alexander 2007), it is the type of El Niño in summer rather than in other seasons that is relevant to exert direct influences on EASP. Secondly, it was always ignored that a mixed-type Pacific (MP) El Niño can emerge beyond the EP and CP El Niño in terms of impacts on EASP. The MP El Niño is characterized by strong SST anomalies across both the Nino3 and Nino4 regions. It is well known that atmospheric teleconnection is sensitive to precise location of SST anomaly (Kug et al., 2010). Therefore, an appropriate classification of El Niño in its developing summer is essential to accurately assess its impacts on EASP. Finally, most previous studies explored only the warm phase of the El Niño / La Niña cycle (Kug et al., 2009), which largely reduced the number of samples on record. A recent study by Zhang et al. (2019) showed that a classification of La Niña events on different types is possible and useful. Indeed, we find that the EASP responses to different types of El Niño and La Niña in summer are approximately opposite (see Supplementary Figures S2 and S3). Therefore, the samples of La Niña cases could be added to enhance the signal-to-noise ratio. That is, the La Niña cases, after reversing the sign, are treated as El Niño.

As a further step of investigation, Wen et al. (2019, hereafter WLL19) reported their studies on relevant physical processes relating El Niño and EASP in the developing summer, but without classification of events. They proposed three pathways that can transmit summer El Niño effects from the tropical Pacific to rainfall anomalies in East Asia: 1) the perturbation over the central-eastern tropical Pacific induces circumglobal waves in the subtropical jet; 2) the dipole heating across the equatorial Maritime Continent induces a PJ-like wave train along the East Asian coast; 3) the suppressed heating over Northwest India induces perturbation in the subtropical jet and therefore downstream propagating fluctuation. Now, if the El Niño SST anomaly in the developing summer is classified into different types, the heating position in the equatorial Pacific is changed. How about the mechanism of different types of summer El Niño impacts on EASP? Are they consistent with that proposed in WLL2019 or not? In-depth study of the different types of El Niño influences on circulation could improve our understanding of their impacts on EASP.

In this study, we revisit the impact of different types of El Niño in their developing summer on EASP and furthermore investigate their influencing mechanisms. The classification is directly based on the location of the maximum SST anomalies in the tropical Pacific to produce three types: summer EP El Niño, summer MP El Niño, and summer CP El Niño. The results indicate that the three types of summer El Niño have significantly different impacts on EASP, with summer EP El Niño influence appearing to be dominant. The possible mechanisms of different summer El Niño influences on circulation are related with the heating position change that induces different perturbations in the subtropical jet. The paper is organized as follows. The data and methods are described in section 2. The impacts of different types of El Niño in the developing summer on EASP and its associated circulation anomaly are presented in section 3. Their possible mechanisms are investigated in section 4. A summary and discussion are given in section 5. 


\section{Data and methods}

Our investigation covers the period from 1958 to 2015. Most data used here are the same as already used in WLL19. For the sake of completeness, we summarize their basic characteristics. The first dataset, monthly precipitation compiled by the Chinese Meteorological Data Center, is from the weather-station network operated by the China Meteorological Administration. The domain of our investigation is East China (east of $100 \mathrm{E}$ ) covered by 140 stations. To reduce noise, the precipitation data are reconstructed by using the first 27 leading empirical orthogonal function (EOF) modes, which retain approximately $70 \%$ of the total variance. Main conclusions remain unchanged if the original rainfall data are used. Precipitation anomalies in this work are expressed as relative values (in percentage) to the seasonal climatology. In our investigation, we also use the NOAA monthly precipitation reconstruction data (PREC) (Chen et al. 2004) covering the same period (1958-2015) to assess El Niño-induced atmospheric heating at global scale. Furthermore, the combined precipitation data (GPCP) (Adler et al. 2003) in a shorter period (1979-2015) are also used to check consistency.

Monthly surface skin temperature (SKT) and atmospheric variables gridded at $2.5^{\circ} \mathrm{X} 2.5^{\circ}$ from 1958 to 2015 are from the National Centers for Environmental Prediction-National Center for Atmospheric Research (NCEP-NCAR) reanalysis data (Kalnay et al. 1996). Anomalies of all variables are defined as deviations from their mean seasonal cycle, with long-term trend removed through a third-order polynomial filter. In addition, the Hadley Center Global Sea Ice and Sea Surface Temperature (HadISST, Rayner et al., 2003) SST and the European Center for Medium-Range Weather Forecasts (ECMWR) reanalysis (ERA-40, Dee et al., 2011) atmospheric data are also used for consistency checks, and the main conclusions presented in the paper remain robust, regardless of different sources of data.

In this study, we mainly focus on impacts of different types of El Niño in their developing summer on EASP. We thus use summer El Niño indices to perform our composite analyses, summer El Niño being defined as the boreal summer SST anomaly in the tropical Pacific preceding the mature phase of El Niño in winter. To determine El Niño events, we use the three-month running mean SST anomalies in the Nino-3.4 region $\left(5^{\circ} \mathrm{S}-5^{\circ} \mathrm{N}, 120^{\circ}-170^{\circ} \mathrm{W}\right)$ to select episodes exceeding the threshold of $+/-0.5^{\circ} \mathrm{C}$ for a minimum of 5 consecutive overlapping seasons (http://www.cpc.ncep.noaa.gov/products/analysis_monitoring/ensostuff/ensoyears.shtml). From 1958 to 2015, a total number of 38 El Niño or La Niña events are identified. Based on these events, we determine different types of El Niño according to the maximum SST anomalies frequently occurring in the equatorial Pacific in their developing summer (three-month mean of June, July and August, JJA). Three types of summer El Niño are identified by the location of maximal SST anomalies: $5^{\circ} \mathrm{S}-5^{\circ} \mathrm{N}, 130^{\circ} \mathrm{W}-80^{\circ} \mathrm{W}$

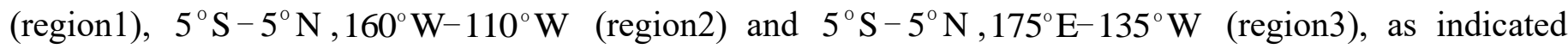
by the blue boxes in Fig. 1. When the SST anomaly center in El Niño developing summer (at least 
greater/less than $+/-0.5^{\circ} \mathrm{C}$ ) falls into one of the above three regions, it is then categorized as an event of summer EP, MP and CP El Niño, respectively. As listed in Table 1, 12 EP, 5 MP and 4 CP summer El Niño are identified. The composite analysis is performed through a difference between the warm and cold events (warm minus cold, then divided by 2). The statistical significance is examined by the student's t-test. Some non-typical cases are excluded from our analysis, such as the 2010 La Niña with competing anomaly centers over region1 and region3, and the 1994 El Niño with the maximum SST anomaly out of the equatorial Pacific. The 1963 summer MP El Niño was also excluded from the composite analysis due to its proximity to the big volcanic eruption of Mt Agung in March 1963 which strongly perturbed the atmospheric circulation (Graf et al., 2014), and also due to inconsistent wind anomalies at $850 \mathrm{hPa}$ found in NCEP and ERA-40. In addition, we also examed the composite analysis using high-pass filter data (which is removed any variability longer than 8 years), but the results remained qualitatively unchanged.

To evaluate the wave energy propagation in a zonally asymmetric climatological mean flow, the wave activity flux defined by Takaya and Nakamura (2001) is used. The method has been specifically introduced in the paper of WLL19, and therefore we will not repeat it here.

\section{Impacts of Different Types of Summer EI Niño on East Asian Precipitation}

As shown in Figs. 1a, c and e, there are significant differences among the three types of summer El Niño in terms of anomalous SST locations. In summer EP El Niño case (Fig. 1a), SST anomalies extend westward from the Peruvian coast along the equatorial Pacific, with the strongest anomalies appearing in the Nino1-2 regions and a portion of the Nino3 region. This pattern roughly resembles the conventional El Niño pattern, except that the SST anomaly is slightly narrower and mainly confined to the eastern Pacific, because boreal summer El Niño is still in its developing stage. In summer MP El Niño case (Fig. 1c), the ellipsoidal SST anomaly distribution is quite different from that of summer EP El Niño, with the anomaly center being approximately 30 longitudes away from the west coast of equatorial South America. The mean SST anomaly in the blue box is about $1.1^{\circ} \mathrm{C}$, which is slightly smaller than that of summer EP E1 Niño (approximately $1.3^{\circ} \mathrm{C}$ ). In contrast to summer EP and MP El Niño, the SST anomaly of summer CP El Niño is located further west and close to the dateline, with the anomaly center reaching to about $0.9^{\circ} \mathrm{C}$ (Fig. 1e). Overall, the SST anomaly centers of the different types of summer El Niño shift eastward by approximately $10^{\circ} \sim 15^{\circ}$ longitudes, compared to the mature phase of El Niño in boreal winter, which are defined based on the SST anomaly locations in the Nino3, 3.4 and 4 regions (Kug et al., 2009). We note that, due to the complexity of the evolution of El Niño, the selected cases of different types of summer El Niño are not exactly the same as those selected in winter. For instance, more EP cases appear in the developing summer, while more MP and $\mathrm{CP}$ cases are observed in winter. Since the atmospheric response is primarily sensitive to the location of tropical heating (Barsugli and Sardeshmukh, 2006), the different types of summer El Niño are inferred to have different climate effects as follows. 


\section{a. Precipitation anomalies}

We now perform a composite analysis based on summer El Niño indices defined in Section 2. To evaluate the relative importance of El Niño SST forcing on EASP in the developing summer, we first examine the SST anomalies over the globe in the Supplementary Figure S1. Besides the dominant SST anomalies in the tropical Pacific, only very weak SST anomalies are found in rest of the global ocean for all the three types of summer El Niño. This indicates that direct impacts of summer El Niño on EASP are expected.

Corresponding to summer EP, MP and CP El Niño, there are significantly different precipitation responses over East Asia. For summer EP El Niño (Fig. 1b), there is a dipole-pattern precipitation response with dryness in North China and wetness in Southeast China. The response amplitude is about $15 \%$ (per $1{ }^{\circ} \mathrm{C}$ change of SST in the eastern tropical Pacific, as indicated by the blue box in Fig. 1a) in most areas of East China, which passes the $90 \%$ confidence level. The composite chart for summer EP El Niño resembles the generalized equilibrium feedback assessment (GEFA) response of EASP to the leading EOF mode of the summer SST anomaly in the tropical Pacific (see Fig. 3 of Wen et al. 2015). This reveals the dominant role of EP El Niño on EASP in summer. In summer MP El Niño case, the precipitation response in East Asia is very different from that of summer EP El Niño. It shows a pronounced tripole pattern in South China with anomalous wet conditions along the Yangtze-Huaihe River valley and anomalous dry conditions in southern and northern China (Fig. 1d). In addition, in northeast China, there are sporadic dry and wet regions. The response amplitude in South China is about $20 \sim 30 \%$ of the summer mean precipitation, scaled to $1{ }^{\circ} \mathrm{C}$ change of SST in the east-central tropical Pacific. In case of summer CP El Niño, the precipitation anomaly (Fig. 1f) presents a triangle pattern with dryness in the Jianghuai region (which is the lower reaches of the Yangtze-Huaihe River valley) and wetness in southern and northern China. Robust precipitation anomalies are mainly confined to the Jianghuai region and to southern China with maximum amplitude reaching 20 30\%. This is roughly consistent with Feng et al. (2016). Although summer MP El Niño and CP El Niño have weaker SST anomalies, their precipitation responses (Figs. 1d and 1f) are larger than that of summer EP El Niño, which reveals a higher sensitivity of EASP to summer MP El Niño and CP El Niño. This is expected and certainly in relation to the background SST distribution along the equatorial Pacific, with a cold tongue in the east and a warm pool in the west.

From the above analysis, it is clear that there are distinct precipitation responses in East Asia to the three types of summer El Niño. To verify the robustness of the signal against noise, we further calculate the spatial pattern (over East China, east of 100E) correlation coefficient of precipitation anomalies between the ensemble mean and their individual members for each of the three types of summer El Niño. As shown in Table 1, most EP events have good correlation coefficients with its ensemble mean (around 0.4 0.7), except two cases (1976/77 El Niño and 2007/08 La Niña). This indicates the major contribution of summer EP El 
Niño forcing to EASP anomaly in their individual cases. For summer MP El Niño, although there are only five samples, the divergence among samples is small and all of them individually resembles the ensemble mean (Fig. 1d) with spatial pattern correlation coefficients around $0.4 \sim 0.7$, which implies a high signal-to-noise ratio. The same conclusion is also valid in summer CP El Niño case, with correlation coefficients around $0.4 \sim 0.8$. In short, classification of the three types of summer El Niño could well group the East Asian precipitation anomaly in El Niño developing summer. Furthermore, the pattern correlations for the three types of summer El Niño generally show positive values for the warm phase of ENSO and negative values for the cold phase, which roughly indicates a linear response of EASP (as shown by the Supplementary Figures S2 and S3).

\section{b. Circulation anomalies}

\section{1) Global circulation}

We now examine the El Niño-induced global atmospheric circulation anomalies in their three-dimensional structure.

For summer EP El Niño, the pronounced characteristics of the circulation response are the mid-latitude low-pressure belt at upper level and the meridional wave train along the East Asian coast at low level. As shown in Figs. 2a and 2b, in the tropics, the main signal is located over the tropical Pacific. It presents a pair of Rossby waves straddling the central equatorial Pacific with amplitude of $\sim 10 \mathrm{~m}$ at $200 \mathrm{hPa}$, resembling the Matsuno-Gill pattern in response to tropical heating (Matsuno 1966; Gill 1980). At low level of atmosphere, 850-hPa anomalous westerlies converge eastward over the east-central equatorial Pacific, which results in a broad strong air ascent in the middle troposphere. In contrast to the tropics, the mid-latitude atmosphere in the Northern Hemisphere exhibits a robust low-pressure ring belt at the upper level. Superimposed on the low-pressure belt, a circumglobal wave train with anomalous cyclone centers over the Mediterranean, Northeast Asia, the Central-North Pacific, off the California coast, the Great Lakes and the North Atlantic, as well as an anomalous anticyclone over Northwest Canada. These anomaly centers generally pass the $90 \%$ confidence level with amplitude around $20 \sim 30 \mathrm{~m}$. At low level, a clear meridional wave train along the coast of East Asia is observed with an anomalous cyclone shrunken over the western tropical Pacific, an anomalous anticyclone over the western North Pacific and an anomalous cyclone over East Asia-Northeast Pacific (denoted as ' $\mathrm{C}-\mathrm{A}-\mathrm{C}$ ' in Fig. 2b). This wave train resembles the so-called 'brother' Pacific-Japan (PJ) pattern in boreal summer (Kosaka and Nakamura, 2010). In general, the characteristics of the circulation response to summer EP El Niño resemble those of the atmospheric response to the summer El Niño in the developing summer (as shown in WLL19), due to the predominance of EP El Niño.

Unlike summer EP El Niño, the prominent features of the atmospheric circulation for summer MP El Niño are the tropical high-pressure belt at upper level and the westward shift of the meridional wave train 
on the East Asian coast at low level (Figs. 2c and 2d). The entire tropics are dominated by high pressures with a robust pair of Rossby waves across the equatorial central Pacific at upper level, as shown in Fig. 2c. The response amplitude is about 10 20 $\mathrm{m}$. This is quite different from the summer EP El Niño, where the zonal-mean geopotential height response in the tropics is almost zero. At low level, the westerly anomalies extend from the western equatorial Pacific to the central Pacific, accompanying a concentrated strong air ascendance to the east of the dateline (Fig. 2d). The ascending flow is slightly westward shifted relative to the flow of summer EP El Niño, which is consistent with the position change of summer MP El Niño SST forcing. Compared with the tropics, the mid-high latitude atmospheric response is relatively weak at upper level, as indicated in Fig. 2c. It shows an ambiguous wave train-like response at mid latitudes with slightly discernable anomalous cyclones over the Iranian Plateau, Northeast Asia, off the California coast, and the Northwest Atlantic. At high latitudes, there is a moderate wave train response from far Northwest Russia through Northeast Asia to the North Atlantic. The corresponding low-level wave train in Fig. 2d indicates the nature of barotropic response. In addition to the zonal wave train at the mid-high latitudes, there is a distinct meridional wave train just right over the East Asian coast at $850 \mathrm{hPa}$ with a broadened anomalous cyclone over the western tropical Pacific, an anomalous anticyclone over South China and the East China Sea, and an anomalous cyclone over Northeast Asia (denoted as ' $\mathrm{C}$ - A - C' in Fig. 2d). The meridional wave train relative to that of summer EP El Niño is displaced westward, especially for the anticyclone over the northwest extratropical Pacific, which has an important influence on the key circulation system over East Asia.

In contrast to summer EP and MP El Niño, the atmospheric response to summer CP El Niño exhibits a distinct zonal wave train at the mid-high latitudes in the Northern Hemisphere. As shown in Figs. 2e and 2f, in the tropical Pacific, the atmospheric response generally resembles the Matsuno-Gill pattern with a pair of upper-level Rossby waves straddling the equatorial Pacific and low-level westerly anomalies along the equatorial Pacific, accompanying ascending airflow over the equatorial central Pacific. The apparent difference from those of summer EP and MP El Niño is the westerly anomaly limited to the west of the dateline and the comparable easterly anomalies to the east of the dateline, which results in a narrow ascending flow over the central Pacific (Fig. 2f). This is consistent with the westernmost SST anomaly forcing of summer CP El Niño in the equatorial Pacific. At mid-high latitudes, the atmospheric response shows a clear zonal wave train with a barotropic structure (Figs. 2e and 2f). It includes six anomalous cyclones over eastern Europe and Russia, central-North China, the Okhotsk, off the west coast of Canada, Northeast Canada, and West Europe, as well as anomalous anticyclones that are generally in between. At low level, besides the corresponding wave train at the mid-high latitudes, there is a robust abnormal cyclone occupying a large area of the western tropical Pacific associated with an anomalous anticyclone over the central North Pacific and a robust cyclone off the west coast of Canada. It appears a meridional wave train propagating northeastward away from the East Asian coast in Fig. 2f.

Although the background circulations of the subtropical jet are all reinforced in the three types of 
summer El Niño, as indicated by the zonal mean of the atmospheric response in the right panels of Figs. 2a, c and e, the cause is however different. For summer EP El Niño (Fig. 2a), the strengthened subtropical jet is related to the low-pressure belt at mid-latitude, while for summer MP El Niño (Fig. 2c) it is caused by the enhanced geopotential height in the tropics. As for summer CP El Niño (Fig. 2e), it is associated with moderate uplift of geopotential height in the tropics and moderate decline of geopotential height at mid-latitudes.

\section{2) Circulation over East Asia}

Now, let us focus on East Asia to see how key circulations are directly related to precipitation anomalies. As shown in Fig. 3, there is a sharp contrast of key circulation anomalies among the different types of summer El Niño. For summer EP El Niño, the dipole precipitation anomaly in Fig. 1b is mainly attributed to the anomalous low pressure in Northeast Asia. While the Western Pacific Subtropical High (WPSH) is normal, a low-pressure anomaly occurs in northeastern Asia at $500 \mathrm{hPa}$, deepening a trough southwestward into South China (Fig. 3a). With the temperature gradient in the southwest-northeast direction (as indicated by the red contours in Fig. 3a), it advects warm air in front of the trough from southern China into the East China Sea, and advects cold air behind the trough from Lake Baikal into southern China. This results in air ascending in southeast China along the coast and air descending in northern China (Fig. 3b), which is coincident with the wet and dry conditions in Fig. 1b. In addition, at low level, the northerly anomalies extend southward to South China along the East Asian coast, and then form an anomalous weak cyclone to its east side (Fig. 3c). The convergent airflows transport a large amount of water vapor from the adjacent region of the South China Sea and the western North Pacific to South China. Eventually, the enhanced ascending air and moisture supply from the south intensify rainfall in Southeast China, and the strong descending flow and cold dry air from the north lead to droughts in northern China (Fig. 1b).

For summer MP El Niño, the precipitation anomaly over East Asia shown in Fig. 1d is mainly attributed to two key circulation anomalies: an anomalous low pressure in Northeast Asia and an anomalous anticyclone in the western North Pacific (Figs. 3d, e and f). Similar to summer EP El Niño, there is an anomalous low pressure in Northeast Asia at $500 \mathrm{hPa}$. But it shifts slightly southward with the east-west trough over central China, which is different from that of summer EP El Niño in the north-south direction (Fig. 3a). This is due to the blocking effect of an anomalous anticyclone in the south. Corresponding to the expansion of the upper-level tropical high-pressure belt into the extratropics (Fig. 2c), an anomalous anticyclone at $500 \mathrm{hPa}$ covers the western extratropical Pacific and southern China, strengthening the westward shift of WPSH toward southeast China (as indicated by the dark red dash contour in Fig. 3d). This leads to a confrontational situation with the anomalous low pressure in the north and the westward intensified subtropical high in the south. As a result, the cold dry air from the north and the warm moist airflow from the south converge over the Yangtze-Huaihe River valley, leading to ascending motion and 
abundant rainfall there (as shown in Figs. 3e and 3f). In addition, the anomalous anticyclone-induced subsidence results in abnormal dryness in southern China (Fig. 3d). However, North China and Northeast China are located at the west flank and center of the low-pressure anomaly respectively, and therefore it results in the rain deficiency in North China and the anomalous rainfall in Northeast China (Fig. 1d). Overall, the characteristics of the westward extension of the WPSH ridge (Fig. 3d), the straight westerly airflow at mid latitudes over East Asia (Fig. 3f), and even the Ural blocking in the middle and upper troposphere (Fig. 2c) are typical features of the Meiyu circulation (Zhang and Tao, 2003). Therefore, the precipitation response to summer MP E1 Niño (Fig. 1d) enhances the variability of the Meiyu in East Asia. It is to be noted that Yuan and Wang (2019) also showed that the spatial configuration of the anomalous cyclone over Northeast Asia and the WPSH can play an important role for the decadal variations of ENSO impacts on autumn precipitation in East China.

For summer CP El Niño, the key circulation to produce the precipitation anomaly shown in Fig. 1f is the anomalous cyclone over central-north China. As shown in Fig. 3g, there is a low-pressure anomaly at $500 \mathrm{hPa}$ occupying most area of East China, which is connected to a strong low-pressure anomaly in far Northeast Asia. This produces two shallow troughs: one along the Hetao Valley in North China, and the other over the east Yungui Plateau along the northeast direction of the mountain. With the climatological temperature gradient in the southwest-northeast direction, it results in an ascending motion in front of the troughs, which corresponds to the anomalous wetness in northern and southern China (Fig. 3h). At low level, there is a meridional wave train away from the East Asian coast (Fig. 2f), with an expansive cyclone anomaly over the western extratropical Pacific and the South China Sea (Fig. 3i). The accompanying northerly anomalies along the East Asian coast weaken the East Asian summer monsoon and therefore result in a shortage of water vapor transport to the Jianghuai region and to Northeast China. The circulation anomalies over East Asia look like those of summer EP El Niño, but the precipitation pattern is quite different. This is mainly due to the slight position change of the low-pressure anomaly over Northeast Asia and the northerly anomalies along the East Asian coast, which indicates precipitation sensitivity associated to the circulation anomalies. In addition, although the weakened East Asian summer monsoon and anomalous cyclone over the western tropical Pacific are consistent with the findings of Weng et al. (2009) and Feng et al. (2016), it is believed that the low-pressure anomaly over central-north China is more important for determining the precipitation pattern (Fig. 1f).

In the three cases, all scenarios involve a meridional propagating wave train along the East Asian coast, but the slight position change of the wave train has a huge influence on EASP. In summer EP and CP El Niño cases, the wave train is a bit eastward and away from the coast of East Asia, and therefore they have little contribution to EASP. However, in summer MP El Niño case, the main part of the meridional wave train is just placed over the East Asian coast, which makes an important contribution to precipitation anomalies in East Asia. 


\section{Mechanism investigation}

In response to the three types of summer El Niño, the significant difference in precipitation anomalies over East Asia is accompanied by a remarkable difference in atmospheric circulation changes. At upper level, the major features of the atmospheric response are the mid-latitude low pressure belt for summer EP El Niño, the overall uplift of geopotential height in the tropics for summer MP El Niño and the wave propagation along mid-high latitudes for summer CP El Niño. At low level, the difference is the slight position change of the meridional wave train along the East Asian coast among the three types of summer El Niño. The following question is how these types of summer El Niño generate distinct circulation anomalies, in association with the location change of SST forcing along the equatorial Pacific.

\section{a. Associated tropical heating}

Similar to WLL19, we first examine summer El Niño-induced tropical precipitation anomalies, in view of the efficiency of tropical heating on the atmosphere. For the three types of summer El Niño, as shown in Fig. 4, the common features of tropical heating are as follows: 1) the east-central tropical Pacific heating associated with the vertical motion; 2) the dipole heating across the equatorial Maritime Continent; and 3) the suppressed heating over India. They are roughly consistent with what presented in WLL19 for the general heating structure of summer El Niño.

However, with the westward shift of SST anomalies along the equatorial Pacific, tropical heating sources also show difference in terms of their relative location, spatial scale and intensity. For summer EP El Niño (Figs. 4a and 4b), the two rainfall datasets consistently show a large-scale precipitation anomaly in the equatorial Pacific, with an elongated distribution of excessive rainfall from the western to eastern equatorial Pacific surrounded by deficient rainfalls over the Maritime Continent and equatorial South America. This shifts the climatological precipitation toward the equatorial central Pacific. In addition, there is an apparent deficiency in rainfall over India and to its north, which is induced by the anomalous anticyclone over the tropical Indian Ocean that breaks the Indian monsoon westerlies (Fig. 2b). For summer MP El Niño (Figs. $4 \mathrm{c}$ and $4 \mathrm{~d}$ ), the precipitation anomaly in the equatorial Pacific is relatively weak and narrow in space. The positive precipitation anomaly in the equatorial Pacific is broken into two comparable centers: one is located in the east-central tropical Pacific, and the other is over the western tropical Pacific. Compared with summer EP El Niño, the precipitation anomaly over the western tropical Pacific strengthens westward and slightly expands poleward. In addition, there is a slight deficiency of rainfall in Northern India. In contrast to summer EP and MP El Niño, the positive precipitation anomalies over the east-central tropical Pacific and the negative precipitation anomalies over the Maritime Continent and over equatorial South America are further weakened for summer CP El Niño (as shown in Figs. 4e and 4f). However, the precipitation anomaly over the western tropical Pacific is largely intensified northwestward with abundant rainfall to east of the Philippines (indicated by the dashed contours in Figs. 4e and 4f). Furthermore, the negative precipitation 
anomaly over India is more pronounced in summer CP El Niño than in other two types of summer El Niño.

In addition to the significant precipitation anomalies in the tropics, there are also distinct rainfall responses in the extratropics mainly occurring along the East Asian coast (Fig. 4). The precipitation anomalies in East Asia are consistent with the results displayed in Fig. 1, which indicates the robustness of the EASP response to different types of summer El Niño.

\section{b. Atmospheric dynamics}

\section{1) Walker Circulation}

With the westward shift of the El Niño SST anomalies along the equatorial Pacific from EP to MP, and finally to $\mathrm{CP}$, the ascending branch of the anomalous Walker circulation also shifts westward from the east-central equatorial Pacific to the central equatorial Pacific, although the descending branch is relatively stable over the Maritime Continent (Fig. 5). This is roughly consistent with the finding of a westward shift of the Walker circulation in different types of El Niño in Weng et al. (2007). For summer EP El Niño (Fig. 5a), it presents a large-scale Walker circulation anomaly over the equatorial Pacific with a strong air ascent over the east-central Pacific and a dominant air descent over the Maritime Continent. The broad air ascent from $160^{\circ} \mathrm{W}$ to $80^{\circ} \mathrm{W}$ is split into two branches at $120^{\circ} \mathrm{W}$. One gradually turns into easterly in the upper troposphere, which is associated with the Walker circulation. And, the other turns into westerly extending far eastward. A weak subsidence occurs over the tropical Indian Ocean at 60E, and it is eventually merged into the major subsidence over Indonesia. Compared to summer EP El Niño, the scale of the anomalous Walker circulation for summer MP El Niño is relatively small (Fig. 5b). This is due to the westward shift of the air ascent over the east-central equatorial Pacific (across 40 longitudes from $160^{\circ} \mathrm{W}$ to $120^{\circ} \mathrm{W}$ ), with a relatively stable air descent over Indonesia around $120^{\circ} \mathrm{E}$. This is consistent with the westward shift of SST anomalies of summer MP El Niño along the equatorial Pacific. To the east of the ascending air, it shows a clockwise zonal circulation with broad subsidence from the western equatorial Atlantic to East Africa $\left(60^{\circ} \mathrm{W}-60^{\circ} \mathrm{E}\right)$. In contrast to summer EP and MP El Niño, the anomalous Walker circulation for summer CP El Niño (Fig. 5c) is further reduced with a narrow ascending air shifting to the east of dateline around $160^{\circ} \mathrm{W}$ and a weak descending air still over Indonesia. With the westward shift of the anomalous Walker Circulation, a competing clockwise zonal circulation to its east also moves westward with a relatively large subsidence at around $80^{\circ} \mathrm{W}$. Furthermore, there are subtle descending and ascending air masses over equatorial South America and the tropical Indian Ocean respectively (Fig. 5c), which implies the small-scale response of the zonal circulation to summer CP El Niño. In short, the scale and location changes of the anomalous Walker circulation over the equatorial Pacific induce the subordinate zonal circulation change outside the equatorial Pacific.

\section{2) Convergence and divergence}


Accompanying the Walker circulation change, a distinct large-scale convergence / divergence flow outside the tropics is observed and shown in Fig. 6. Consistent with the Walker circulation variation (Fig. 5a), summer EP El Niño produces a dominant divergence center over the east-central tropical Pacific and a considerable convergence center from the subtropical Indian Ocean to the Maritime Continent at upper level (Fig. 6a), and the opposite at low level (Fig. 6b). The large-scale convergence and divergence over the east-central subtropical Pacific and North India provide source of perturbations entering into the subtropical jet (WLL19). Besides, there is a subordinate convergence just at the entrance of the south branch of subtropical jet over the North Atlantic, which might be another entry point of perturbations in the subtropical jet. Relative to summer EP El Niño, summer MP El Niño-induced convergence and divergence at upper level (Fig. 6c) are reduced in spatial extension, with a westward shift of divergence center over the east-central tropical Pacific and two comparable convergence centers over the Maritime Continent and Northwest Africa. Since the convergence over the Maritime Continent is confined within the tropics, perturbations circulating in the subtropical jet are obviously related to the other two convergence / divergence centers and mainly located over the east-central subtropical Pacific and Northwest Africa. For summer CP El Niño (Figs. 6e and 6f), in addition to the dominant divergence over the central tropical Pacific, there are weak convergence centers over the Maritime Continent and equatorial South America at upper level, and the opposite at low level. Although the two centers are limited to the tropics, their extended convergence into the extratropics provides the opportunity for the perturbations over North Africa and North India to propagate into higher latitudes. Therefore, for summer CP El Niño, the source of perturbations might be from the east-central subtropical Pacific, North Africa, and North India.

In addition to the direct source of perturbations for the subtropical jet, there might also involve the indirect perturbation through the monsoon trough. As shown by the velocity potential at low level (Figs. 6b, $\mathrm{d}$ and $\mathrm{f}$ ), all three types of summer El Niño have subordinate convergences over the western tropical Pacific with a slight shift of location. This provides a potential source of perturbations into the monsoon trough and therefore leads variations in the subtropical jet.

\section{3) Wave Activity Flux}

Different perturbations in the subtropical jet can result in different circulation responses, especially at upper levels. To evaluate the wave energy propagation in the mean flow, the wave activity flux is calculated and displayed in Fig. 7. It can help us to discuss possible ways for the different types of summer El Niño to generate atmospheric circulation anomalies over East Asia (Fig. 2).

Summer EP El Niño is likely to affect the extratropical atmospheric circulation (Figs. 2a and 2b) through three pathways, similar to those described in WLL19. Firstly, as shown by the wave activity flux at upper level in Fig. 7a, the vertical motion-induced perturbation over the east-central tropical Pacific, through the westerly trough over the east-central subtropical Pacific, could effectively convey the flux from the tropics to extratropics, and excite eastward-propagating waves along the jet over North America with tilt to 
northeast. In addition, the downstream propagation of the energy along the jet might also involve the relay effect of the perturbation at the entrance of the south branch of subtropical jet over the North Atlantic, as indicated by the communication of the energy flux from the North Atlantic in Fig. 7a. Secondly, the anomalous cyclone over the western tropical Pacific at low level (Fig. 2b), which is caused by the Rossby wave response to the SST anomaly in the eastern tropical Pacific, produces abundant rainfall there (Figs. 4a and $4 \mathrm{~b}$ ). The northwestward-extended precipitation anomaly perturbs the western Pacific monsoon trough and further excites the northward-propagating Rossby wave train along the East Asian coast, as indicated by the wave flux over the western North Pacific (Fig. 7b). Thirdly, the subsidence over the southwest Maritime Continent causes the anomalous anticyclone over the tropical Indian Ocean (Wang et al., 2003). Its associated suppressed heating over North India induces convergence and divergence at upper and lower levels, which is collocated with the northwest-tilt center of the velocity potential there (Figs. 6a and 6b). The perturbation is so close to the subtropical jet that it provides another way to trigger wave propagation downstream in the westerly waveguide (Fig. 7a). In short, the three ways connecting tropical perturbations to the atmospheric circulations are consistent with those proposed in WLL19, which indicate the major contribution of summer EP El Niño to driving atmospheric circulation anomalies in El Niño developing summer.

For summer MP El Niño, the heating position change-induced perturbations use a very different way to influence the atmospheric circulation, especially at upper levels. As shown in Fig. 7c, a wave flux emits from the east-central tropical Pacific toward the extratropics along the westerly trough over the subtropical North Pacific. However, it seems ineffective in stimulating downstream waves in the westerly jet, as indicated by disrupted flux propagation over the North Atlantic. This might be related to the absence of energy transfer over the extratropical North Atlantic, as in the case of summer EP El Niño. However, the convergence over Northwest Africa (Fig. 6c) plays an important role in stimulating the wave train in mid-high latitudes due to its proximity to the subtropical jet also its particular position at the west side of the South Asian High, where climatological wind is southerly. According to Wang et al. (2005), the southerly basic flow may transfer Rossby wave sources northward even for a forcing embedded in the deep tropics, which provides a possibility for perturbations over Northwest Africa to excite Rossby waves at mid-high latitudes, as shown in Fig. 2c. This might interrupt the energy propagation from the east-central subtropical Pacific to downstream areas along the subtropical jet. As a consequence, the large amount of energy induced by summer MP El Niño is mainly confined to the tropics, which leads to the general rise of geopotential height over the tropics through the Kelvin wave adjustment along the equator (Kumar and Hoerling, 2003). At low levels of the atmosphere, nevertheless, a strong meridional propagating flux is observed from the western tropical Pacific to Northeast Asia (Fig. 7d). This meridional wave train just over the East Asian coast makes an important contribution to the observed tripole-pattern precipitation anomalies, as discussed in Figs. 3d, e and f. The westward shift of the wave train (Fig. 2d) is likely due to the northwestward shift of MP El Niño-induced precipitation anomalies over the western tropical Pacific and therefore the slight 
position change of perturbations into the monsoon trough.

Summer CP El Niño shows a competing effect of perturbations for their impact on the atmospheric circulation. As shown in Fig. 7e, a clear energy flux propagates from the east-central tropical Pacific to the extratropics along the westerly trough over the subtropical North Pacific. It propagates downstream along the westerly jet, showing weak interaction with the circulation over the extratropical North Atlantic. That is certainly due to the fact that perturbations over equatorial South America are slightly far away from the entrance of the westerly jet over the North Atlantic. The wave flux in Fig. 7e also shows an apparent eastward propagation confined in the westly jet across Eurasia, the North Pacific, until West America, which is probably attributable to the suppressed heating over North India. The anomalous anticyclone in relation to the subsidence over the Maritime Continent (Fig. 2f) provokes exceptional dryness over India (Figs. 4e and 4f), triggering perturbations in the subtropical jet and downstream propagating waves. This could be further verified by the wave train pattern over Eurasia in Fig. 2e, which is similar to the atmospheric response to heating over North India (e.g., Fig. 11c in WLL19). In addition, like in summer MP El Niño case, the perturbation over North Africa launches the wave train from North Africa to mid-high latitudes, as indicated by the meridional wave flux along $20^{\circ} \mathrm{E}$ in Fig. 7e. The wave train, especially the anticyclone centers (Fig. 2e), is collocated with the wave train of summer MP El Niño (Fig. 2c), which further supports the idea that perturbations over North Africa may excite the observed atmospheric response. However, at low level, a distinct energy flux emits from the western Pacific to the west coast of Canada along with the westerly wind (Fig. 7f). Precipitation anomalies over the western tropical Pacific extend far northwestward (Figs. 4e and 4f), providing high efficiency for them to enter into the monsoon trough and therefore to stimulate the meridional wave train along the East Asian coast. The penetration of perturbations into the subtropical jet excites downstream waves over the North Pacific, which contributes to the fluctuations shown in Fig. 2e.

\section{Summary and Discussions}

This paper focuses on the impacts of different types of El Niño in their developing summer on East Asian summer precipitation (EASP) for the period from 1958 to 2015. The events are classified into three types: summer eastern Pacific (EP) El Niño, summer mixed-type Pacific (MP) El Niño and summer central Pacific (CP) El Niño. Their corresponding precipitation anomalies in East Asia differ significantly. For summer EP El Niño, it presents a south-north dipole response with anomalous dry conditions in North China and anomalous wet conditions in Southeast China. For summer MP El Niño, there is a tripole-pattern precipitation anomaly with excessive rainfalls along the Yangtze-Huaihe River valley and deficient rainfalls in South and North China. For summer CP El Niño, the precipitation anomaly shows distinct wetness in South and North China and robust dryness in the Jianghuai region.

The El Niño-induced key circulations that determine the precipitation anomalies in the three cases depend on the relative position of the low pressure over East Asia and the Western Pacific subtropical High 
(WPSH), as shown by the schematic diagram in Fig. 8. For summer EP El Niño, the dipole precipitation anomaly is mainly attributed to a low-pressure anomaly over Northeast Asia, which leads to air ascent in front of the trough and descent behind it. For summer MP El Niño, the confrontational state of the low-pressure anomaly in North China and the westward strengthened WPSH in South China results in convergence flows in the Yangtze-Huaihe River valley and typical Meiyu rainfall. For summer CP El Niño, the key circulation is the anomalous cyclone over central-north China, which provides favorable conditions for air ascending and precipitation anomalies.

Our results reveal distinct precipitation responses to different types of summer El Niño. It helps us to conciliate the controversies in previous studies. The insignificant response of precipitation in South China for the conventional El Niño (Weng et al., 2009; Feng et al., 2016; WLL19) is mainly due to the mixing effect between summer EP and MP El Niño. Separately both summer El Niño show significant precipitation response in South China, but the precipitation anomalies are opposite to each other. Furthermore, summer EP El Niño is much more frequently observed, but summer MP El Niño has large precipitation anomaly in South China (as shown in Fig. 1d). The weak signal in South China is actually from a cancellation effect of summer EP and MP El Niño. This finding permits to explain the results from several previous studies (Yuan and Yang, 2012; Feng et al., 2016), which indicate the influence of their so-called 'EP' El Niño (the conventional El Niño) on East Asian climate was negligible in its developing summer. Our findings actually reveal a dominant impact of summer EP El Niño on EASP.

In addition to impacts on EASP, the three types of summer El Niño also show distinct impacts on the global atmospheric circulation. For summer EP El Niño, the major feature of circulation anomaly is the mid-latitude low-pressure belt at upper level. For summer MP El Niño, the atmospheric response at upper level is mainly confined to the tropics with an overall uplift of the tropical geopotential height. For summer CP El Niño, the upper-level atmosphere mainly presents a zonal fluctuating wave response at mid-high latitudes. At low level, atmospheric responses to the three types of summer El Niño have the common feature of a meridional wave train along the East Asian coast. But the wave train slightly shifts northwestward from EP to MP, and then to CP, in association with the westward displacement of the SST anomalies along the equatorial Pacific. The distinguishing atmospheric response to the three types of summer El Niño especially at upper level is mainly ascribed to the different SST anomalies and their induced changes of large-scale convergence / divergence flows, which exert different perturbations in the subtropical westly jet and therefore result in a different atmospheric response over East Asia.

The physical mechanisms of the different types of summer El Niño to produce the atmospheric responses can be summarized as follows. Summer EP Nino mainly affects circulations through three pathways, very close to what described in WLL19. The first pathway is excited by vertical motion-induced perturbations from the east-central tropical Pacific. The perturbations enter into the westerly trough over the subtropical North Pacific and enable circumglobal Rossby waves propagating along the subtropical jet. The second one is that the heating perturbations over the western tropical Pacific through the monsoon trough 
excite the meridional wave train along the East Asian coast. The third is the El Niño-induced indirect heating over North India that triggers perturbations in the waveguide jet. In addition to the second pathway that also operates for the summer MP El Niño, MP has unique ways in influencing atmospheric circulation. The vertical motion-induced perturbations over the east-central tropical Pacific cannot be effectively transmitted into mid-latitudes. This is due to the absence of effective interaction connecting the two westerly jets over the North Atlantic and the presence of a blocking effect of the meridional propagation wave from Northwest Africa. A large amount of energy induced by summer MP El Niño is thus confined to the tropics. Furthermore, the upper-level perturbations over Northwest Africa can trigger a hemispheric-scale Rossby wave train at mid-high latitudes. For summer CP El Niño, the atmospheric response at mid-high latitudes involves a competing effect of perturbations over the east-central tropical Pacific, North India, the western tropical Pacific, and North Africa. The fluctuation within the subtropical jet, especially over Eurasia, is mainly due to the suppressed heating over North India.

Overall, our study provides a basic reference for the prediction of summer precipitation in East China with signals from different types of summer El Niño. It provides an exploration of physical mechanisms explaining atmospheric response to different summer El Niño. As a perspective for pursuing the current work, we will perform numerical simulations to quantify atmospheric responses to each heating, and to investigate how different perturbations interact together to generate the observed atmospheric response.

\section{Acknowledgement}

Authors thank Prof. Zhengyu Liu and Tim Li for the constructive discussions. This work is supported by Chinese NSFC41475089. L Li acknowledges the support of the National Key Research and Development Program of China (Grant-2018YFC1507704). 


\section{References}

1. Adler, RF, Huffman GJ, Chang A, et al., 2003, The Version-2 Global Precipitation Climatology Project (GPCP) Monthly Precipitation Analysis (1979-Present). J Hydrometeor, 4:1147-1167

2. Alexander MA, Blade I, Newman M, et al., 2002, The atmospheric bridge: the influence of ENS0 teleconnections on air-sea interaction over the global oceans. J Clim, 15:2205-2231

3. Ashok K, Behera SK, Rao SA, et al. 2007, E1 Niño Modoki and its possible teleconnection. J Geophys Res, $112(\mathrm{C} 11007)$

4. Barsugli JJ, Shin SI, Sardeshmukh PD, 2006, Sensitivity of global warming to the pattern of tropical ocean warming. Clim Dyn, $27(5): 483-492$

5. Chen M, Xie P, Janowiak JE, et al., 2004, Verifying the reanalysis and climate models outputs using a 56-year data set of reconstructed global precipitation. Seattle, Wash: Paper Presented at 14th AMS Conference on Applied Climatology, Am Meteorol Soc, J6. 1

6. Chen G, Tam C Y. 2010, Different impacts of two kinds of Pacific Ocean warming on tropical cyclone frequency over the western North Pacific. Geophys Res Lett, 37(1):70-75

7. Dee DP, Uppala SM, Simmons AJ, et al., 2011, The ERA - Interim reanalysis: configuration and performance of the data assimilation system, Quart J Roy Meteorol Soc, 137:553-597

8. Feng J, Chen W, Tam, CY, et a1., 2011, Different impacts of E1 Niño and E1 Niño Modoki on China rainfall in the decaying phases. Int J Climatol, 31(14):2091-2101

9. Feng J, Li J, Zheng F, et a1., 2016, Contrasting Impacts of Developing Phases of Two Types of E1 Niño on Southern China Rainfa11. J Meteorol Soc Jpn, 94(4):359-370

10. Feng J, Li J, 2011, Influence of El Niño Modoki on spring rainfall over south China. J Geophys Res, $116(\mathrm{D} 13102)$

11. Gao H, Wang YG, 2007, On the Weakening relationship between summer precipitation in China and ENSO, Acta Meteorol Sin, 65(1):131-137

12. Gill AE, 1980, Some simple solutions for heat-induced tropical circulation. Quart J Roy Meteorol Soc, $106: 447-462$

13. Graf H, Zanchettin D, 2012, Central Pacific El Niño, the “subtropical bridge, ” and Eurasian climate. J Geophys Res, 117 (D01102)

14. Graf, H.-F., D. Zanchettin, C. Timmreck and M. Bittner, 2014, Observational constraints on the tropospheric and near-surface winter signature of the Northern Hemisphere stratospheric polar vortex. Clim. Dyn., 43: 3245, doi:10. 1007/s00382-014-2101-0

15. Pascolini-Campbe11, M., D. Zanchettin, 0. Bothe, C. Timmreck, D. Matei, J. H. Jungclaus, and H. -F. Graf, 2014, Toward a record of Central Pacific El Niño events since 1880. Theor. Appl. Climatol., doi: 10. 1007/s00704-014-1114-2

16. Hoskins BJ, Karoly DJ, 1981, The steady linear response of a spherical atmosphere to thermal and orographic forcing. J Atmos Sci, 38: 1179-1196 
17. Kalney E, Kanamitsu M, Kistler R, et al., 1996, The NCEP/NCAR 40-year reanalysis project. Bull Amer Meteorol Soc, 77:437-471

18. Kao HY, Yu JY, 2009, Contrasting Eastern-Pacific and Central-Pacific types of ENSO. J Clim, 22(3):615-632

19. Kosaka Y, Nakamura H, 2010, Mechanisms of meridional teleconnection observed between a summer monsoon system and a subtropical anticyclone. Part I: The Pacific-Japan pattern, J Clim, 23:5085-5108

20. Kumar A, Hoerling MP, 2003, The nature and causes for the delayed atmospheric response to E1 Niño. J Clim, $16: 1391-1403$

21. Kumar KK, Rajagopalan B, Hoerling M, et al., 2006, Unraveling the Mystery of Indian Monsoon Failure during E1 Niño. Science, 314(5796):115-119

22. Kug JS, Jin FF, An SI, 2009, Two types of E1 Niño events: Cold tongue E1 Niño and warm pool E1 Niño. J Clim, $22(6): 1499-1515$

23. Kug J-S, Ahn M-S, Sung M-K, et a1., 2010, Statistical relationship between two types of E1 Niño events and climate variation over Korean Peninsula, Asia-Pac J Atmos Sci, 46(4):467-474

24. Larkin NK, Harrison DE, 2005, Global seasonal temperature and precipitation anomalies during El Niño autumn and winter. Geophys Res Lett, 32(16):3613-3619

25. Li ZX, Coni1 S, 2003, Transient Response of an Atmospheric GCM to North Atlantic SST Anomalies. J Clim, $16: 3993-3998$

26. Liu Z, Alexander M, 2007, Atmospheric bridge, oceanic tunnel, and global climatic teleconnections. Rev Geophys, $45(2):$ RG2005

27. Matsuno T, 1966, Quasi-geostrophic motions in the equatorial area. J Meteorol Soc Jpn, 44:25-43

28. Rayner NA, Parker DE, Horton EB, et al., 2003, Global analyses of sea surface temperature, sea ice, and night marine air temperature since the late nineteenth century, J Geophys Res, 108(D14):4407

29. Ropelewski CF, Halpert MS, 1987, Global and Regional Scale Precipitation Patterns Associated with the E1 Niño/Southern 0scillation. Mon Weather Rev, 115(8):1606-1626

30. Song H-J, Choi E, Lim G-H, et al., 2011, The central Pacific as the export region of the E1 Niño-Southern Oscillation sea surface temperature anomaly to Antarctic sea ice. J Geophys Res, 116(D21113)

31. Takaya K, Nakamura H, 2001, A formulation of a phase-independent wave-activity flux for stationary and migratory quasigeostrophic eddies on a zonally varying basic flow, J Atmos Sci, 58:608-627

32. Trenberth KE, Branstator GW, Karoly D, et al., 1998, Progress during TOGA in understanding and modeling global teleconnections associated with tropical sea surface temperatures. J Geophys Res, $103($ C7) : 14291-14324

33. Wang B, Wu R, Li T, 2003, Atmosphere-warm ocean interaction and its impact on Asian-Australian Monsoon variability. J Clim, 16:1195-1211

34. Wang Z, Chang CP, Wang B, et al., 2005, Teleconnections from tropics to Northern extratropics through a southerly conveyor, J Clim, 62:4057-4070

35. Weng H, Ashok K, Behera SK, et al., 2007, Impacts of recent E1 Niño Modoki on dry/wet conditions in the 
Pacific rim during boreal summer. Clim Dyn, 29(2-3):113-129

36. Weng H, Behera SK, Yamagata T, 2009, Anomalous winter climate conditions in the Pacific rim during recent E1 Niño Modoki and E1 Niño events. Clim Dyn, 32(5):663-674

37. Wen N, Liu ZY, Liu YH, 2015, Direct impact of E1 Niño on East Asian summer precipitation in the observation, Clim Dyn, 44:2979-2987

38. Wen N, Liu ZY, Li L, 2019, Direct ENSO Impact on East Asian Summer Precipitation in the Developing Summer, Clim Dyn. 52(11):6799-6815

39. Zhang QY, Tao SY, 2003, The Anomalous Subtropical Anticyclone in Western Pacific and Their Association with Circulation over East Asia during Summer. Chin J Atmos Sci, 27 (3):369-380

40. Zhang W, Wang Z, Stuecker MF, et al., 2019, Impact of ENSO longitudinal position on teleconnections to the NA0. Clim Dyn, 52(1-2):257-274

41. Zhang W, Jin FF, Li J, et al., 2011, Contrasting impacts of two-type E1 Niño over the western North Pacific during boreal autumn. J Meteorol Soc Jpn, 89(5):563-569

42. Zong HF, Chen LT and Zhang QY, 2010, The Instability of the Interannual Relationship between ENS0 and the Summer Rainfall in China, Chinese Journal of Atmospheric Sciences, 34(1):184-192

43. Yeh SW, Kug JS, An SI, 2014, Recent progress on two types of E1 Niño: Observations, dynamics, and future changes. Asia-Pac J Atmos Sci, 50(1):69-81

44. Yeh SW, Kug JS, Dewitte B, et a1., 2009, E1 Niño in a changing climate. Nature, 462 (7263):674-674

45. Yuan Y, Yang S, 2012, Impacts of Different Types of E1 Niño on the East Asian Climate: Focus on ENS0 Cycles. J Clim, 25(21):7702-7722

46. Yuan, C and D. Wang, 2019, Interdecadal Variations in E1 Niño-Southern Oscillation Impacts on the Autumn Precipitation in the Eastern China. International Journal of Climatology, doi:10. 1002/joc. 6156

47. Yuan, C., J. Liu, J. Luo and Z. Guan, 2019, Influences of tropical Indian and Pacific oceans on the interannual variations of precipitation in the early and late rainy seasons in South China. Journal of Climate, doi:10. 1175/JCLI-D-18-0588. 1 
Table1 Corresponding to different summer El Niño, the pattern correlation of the composite East Asian precipitation anomaly with its individual case. For each category, the El Niño and La Niña years selected for composite are separately listed in row. The boldface italic value indicates the $90 \%$ confidence level.

\begin{tabular}{|c|c|c|c|c|c|c|c|c|}
\hline \multirow[t]{4}{*}{ EP } & El Niño Year & 1965 & 1972 & 1976 & 1997 & 2009 & 2014 & 2015 \\
\hline & Prec. Corr. & 0.55 & 0.61 & -0.19 & 0.64 & 0.50 & 0.52 & 0.72 \\
\hline & La Niña Year & 1964 & 1970 & 1984 & 1988 & 2007 & & \\
\hline & Prec. Corr. & -0.57 & -0.34 & -0.49 & -0.46 & -0.20 & & \\
\hline \multirow[t]{4}{*}{ MP } & El Niño Year & 1982 & 1987 & 1991 & & & & \\
\hline & Prec. Corr. & 0.41 & 0.54 & 0.70 & & & & \\
\hline & La Niña Year & 1973 & 1999 & & & & & \\
\hline & Prec. Corr. & -0.52 & -0.64 & & & & & \\
\hline \multirow[t]{4}{*}{ CP } & El Niño Year & 1977 & 2002 & 2004 & & & & \\
\hline & Prec. Corr. & 0.51 & 0.47 & 0.54 & & & & \\
\hline & La Niña Year & 1975 & & & & & & \\
\hline & Prec. Corr. & -0.80 & & & & & & \\
\hline
\end{tabular}




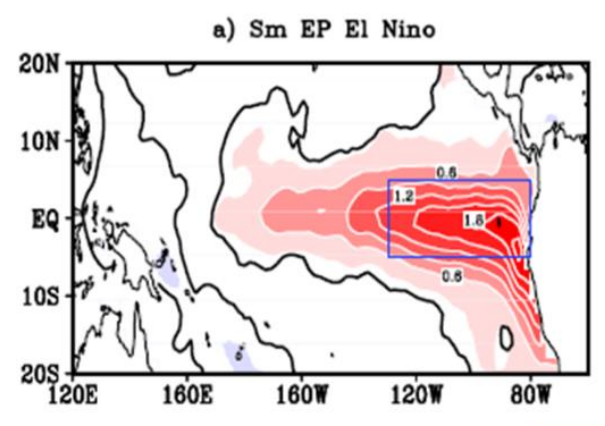

c) Sm MP El Nino

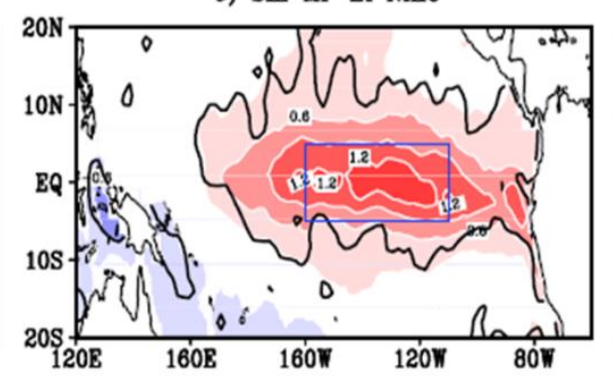

e) Sm CP El Nino

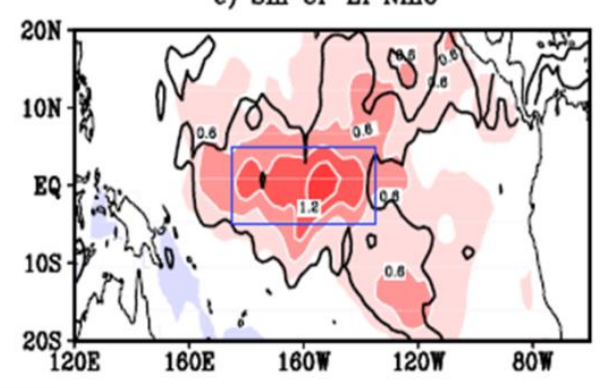

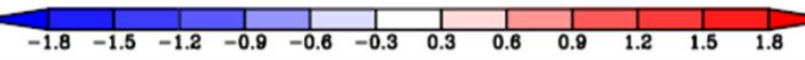

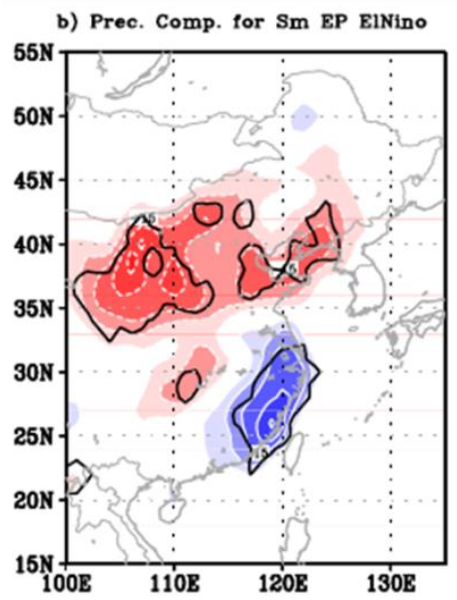

d) Prec. Comp. for Sm MP EINino

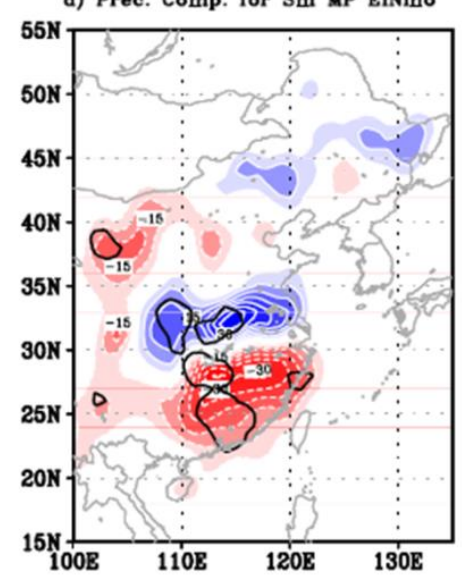

f) Prec. Comp. for Sm CP EINino

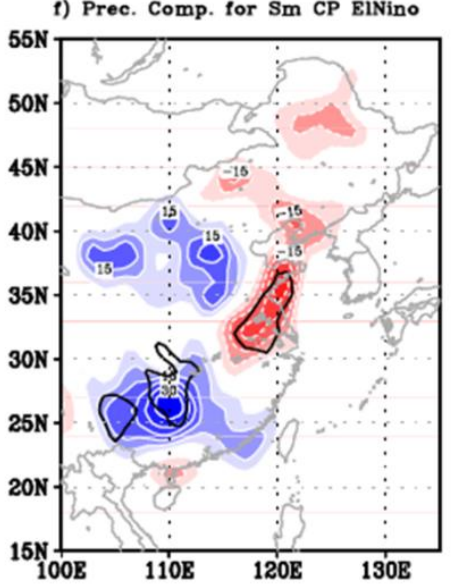

Figure 1 Different types of summer El Niño (a, c, e) and corresponding summer precipitation anomalies over East Asia (b, d, f). a) Summer eastern Pacific (EP) El Niño, cases selected on the base of the maximum SST anomaly (at least greater than $0.5^{\circ} \mathrm{C}$ ) falling into the region $\left(5^{\circ} \mathrm{S}-5^{\circ} \mathrm{N}, 130^{\circ} \mathrm{W}-80^{\circ} \mathrm{W}\right.$ ) (as indicated by the blue box) during the summer preceding the peaks of El Niño. c) Summer mixed-type Pacific (MP) El Niño, based on the maximum SST anomaly over the region $\left(5^{\circ} \mathrm{S}-5^{\circ} \mathrm{N}, 160^{\circ} \mathrm{W}-110^{\circ} \mathrm{W}\right)$. e) Summer central Pacific (CP) El Niño, based on the maximum SST anomaly over the region $\left(5^{\circ} \mathrm{S}-5^{\circ} \mathrm{N}\right.$,

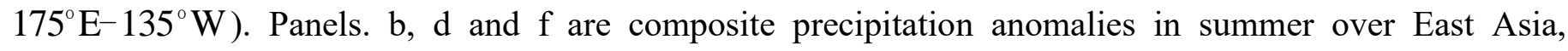
corresponding to summer EP, MP and CP El Niño respectively. In the upper panels, the red (blue) shading with the white solid (dashed) line represents positive (negative) values with contour interval (CI) of $0.3{ }^{\circ} \mathrm{C}$. In the bottom panels, blue (red) shadings with the white solid (dashed) lines denote positive (negative) percentage anomalies relative to climatology with $\mathrm{CI}=5 \%$. The thick black contour indicates the $90 \%$ confidence level. 
a) Z200 Comp. for Sm EP EINino

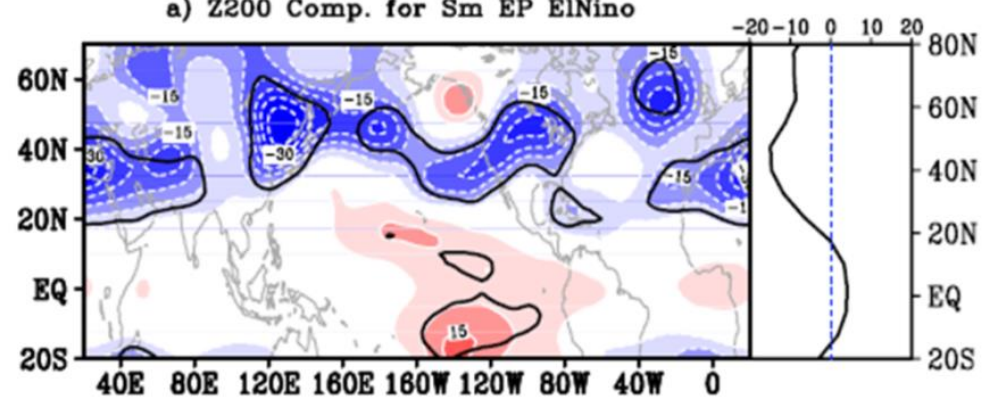

c) Z200 Comp. for Sm MP EINino

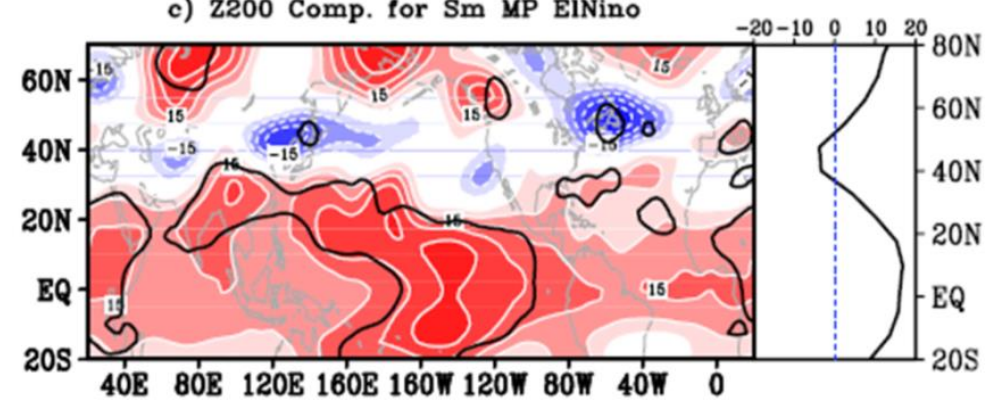

e) Z200 Comp. for Sm CP EINino

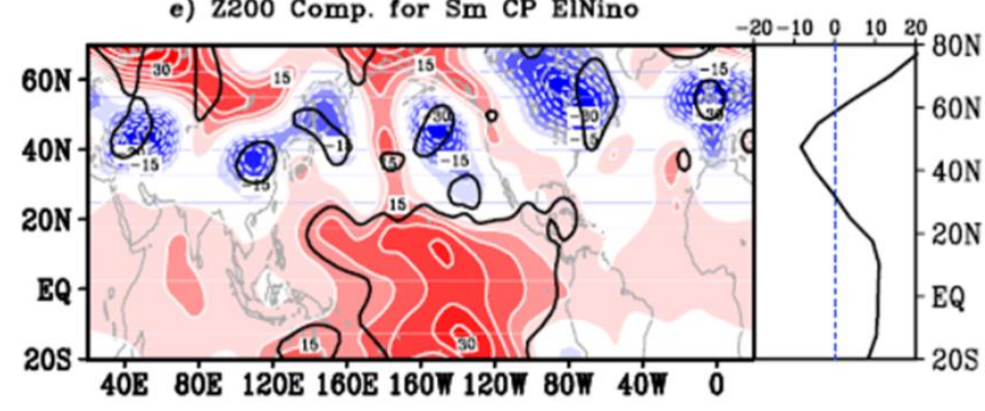

b) uv850/- $\omega 500$ Comp. for Sm EP EINino

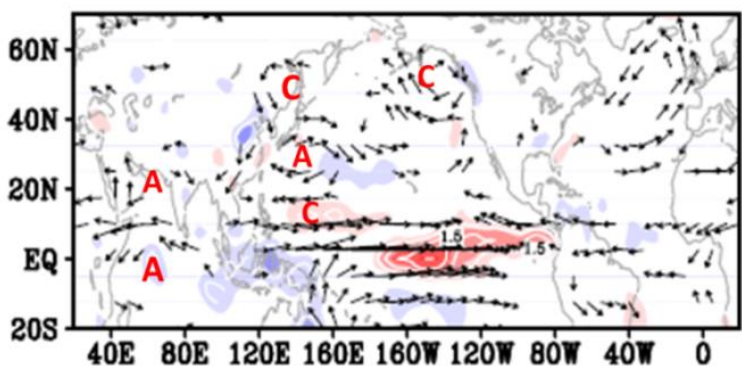

d) uv850/- $\omega 500$ Comp. for Sm MP ElNino

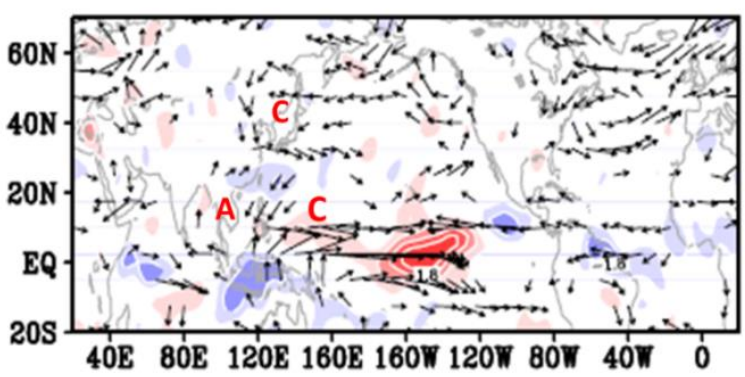

f) uv850/- 5500 Comp. for Sm CP ElNino

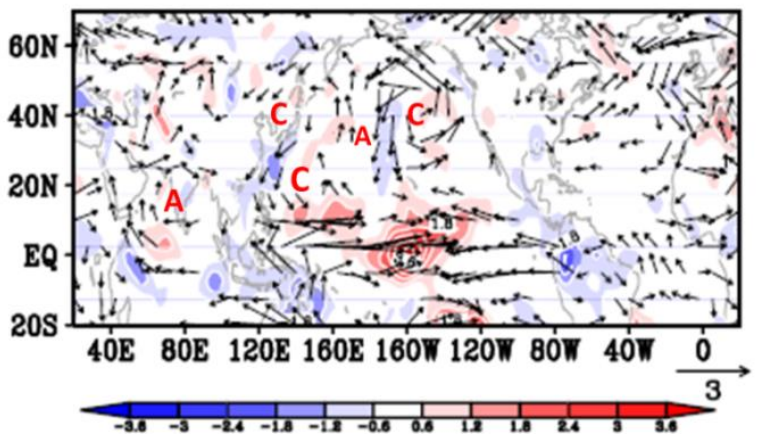

Figure 2 Composite atmospheric anomalies in the tropical-Northern Hemisphere, in association with the different types of summer El Niño. From top to bottom are summer EP, MP and CP El Niño respectively. Left panels (a, c and e) are $200 \mathrm{hPa}$ geopotential height anomalies with their zonal means on the right-hand side. The red (blue) shading with white solid (dashed) lines represent positive (negative) values $(\mathrm{CI}=5 \mathrm{~m})$. The black contours indicate the 90\% confidence level. Right panels (b, $\mathrm{d}$ and f) are anomalies of $850 \mathrm{hPa}$ wind (vector, unit: $\mathrm{m} / \mathrm{s}$ ) and $500 \mathrm{hPa}$ vertical velocity (omega with opposite sign $(-\omega)$, shaded). Small values of wind (magnitude less than $0.3 \mathrm{~m} / \mathrm{s}$ ) are omitted. The red letters " $\mathrm{C}$ " and "A" mark cyclones and anticyclones respectively. The red (blue) shadings with the white solid (dashed) lines $\left(\mathrm{CI}=0.5 \times 10^{-2} \mathrm{~Pa} / \mathrm{s}\right)$ denote the air ascending (descending). 
a) Z500 Comp. for Sm EP EINino

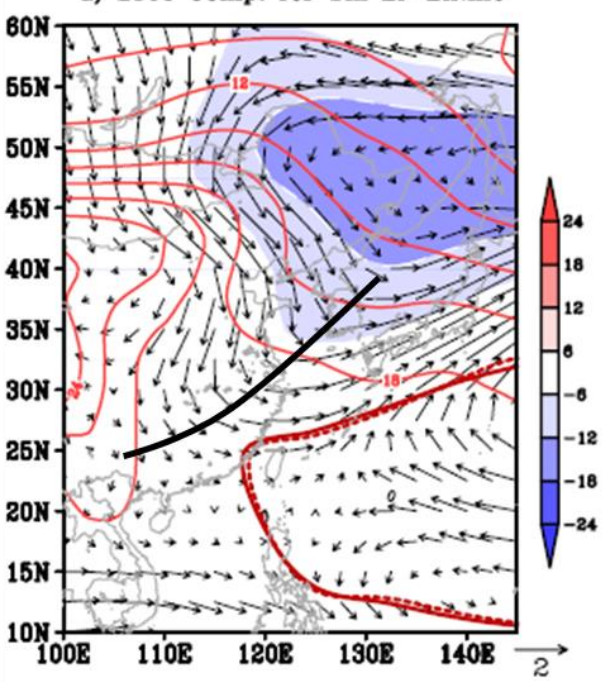

d) Z500 Comp. for Sm MP ElNino

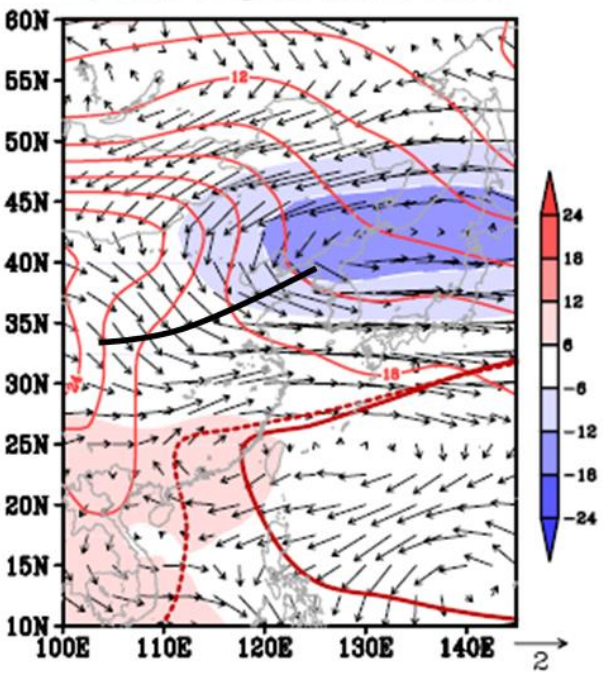

g) Z500 Comp. for Sm CP ElNino

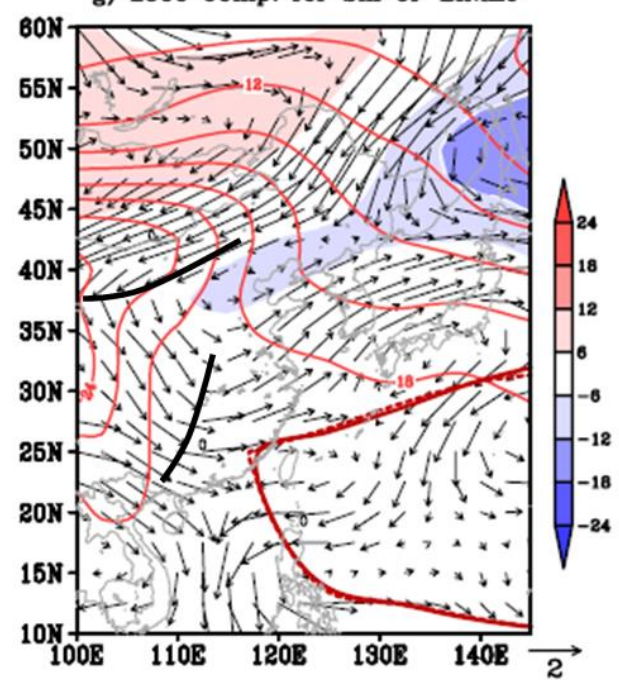

b) -w500 Comp. for Sm EP EINino

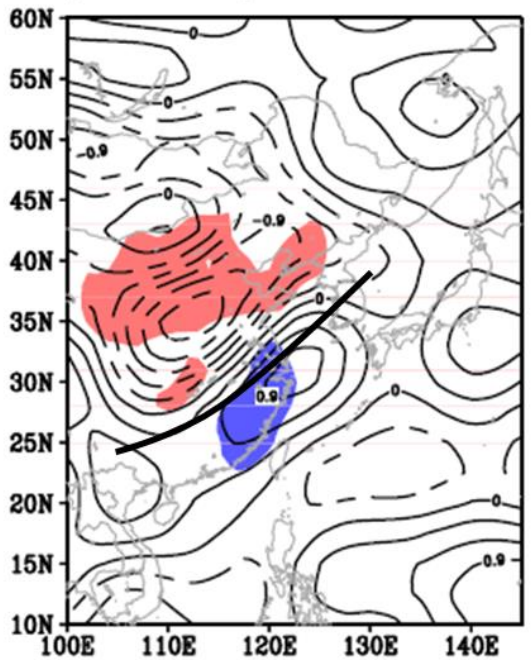

e) $-\omega 500$ Comp. for Sm MP ElNino

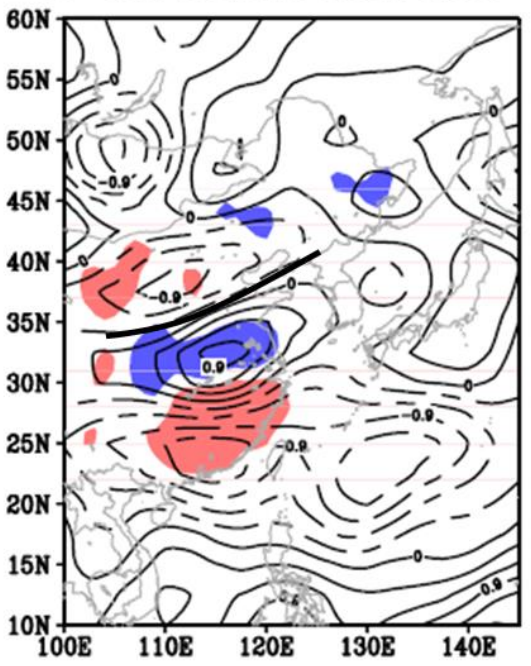

h) $-\omega 500$ Comp. for Sm CP EINino

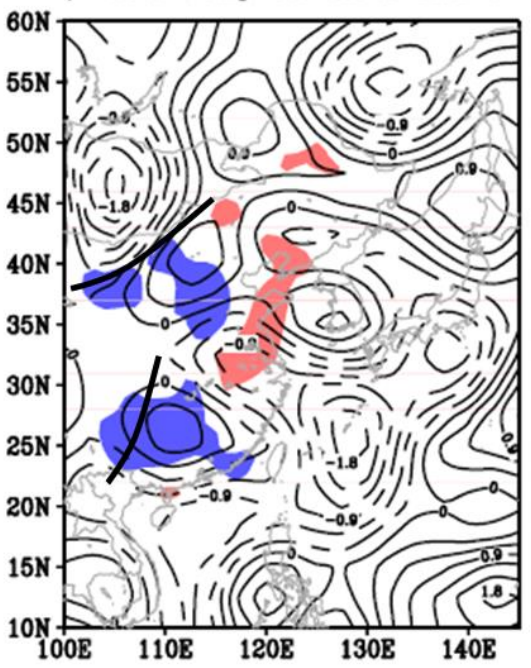

c) uv850 Comp. for Sm EP ElNino

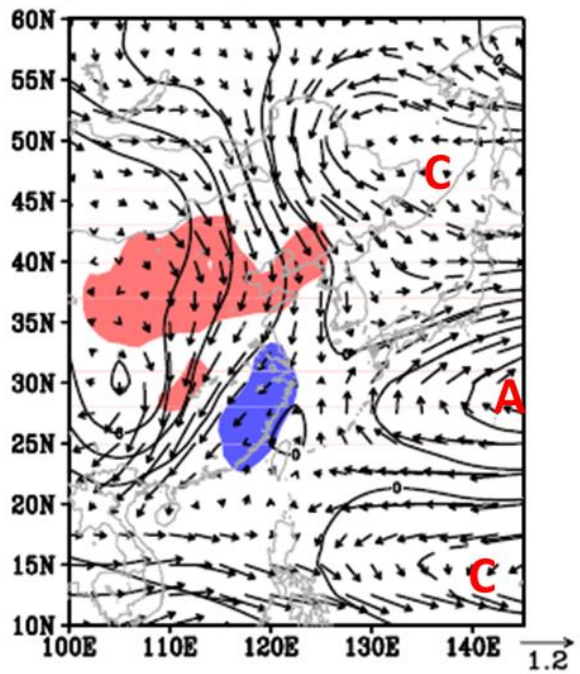

1) av850 Comp. for Sm MP ElNino

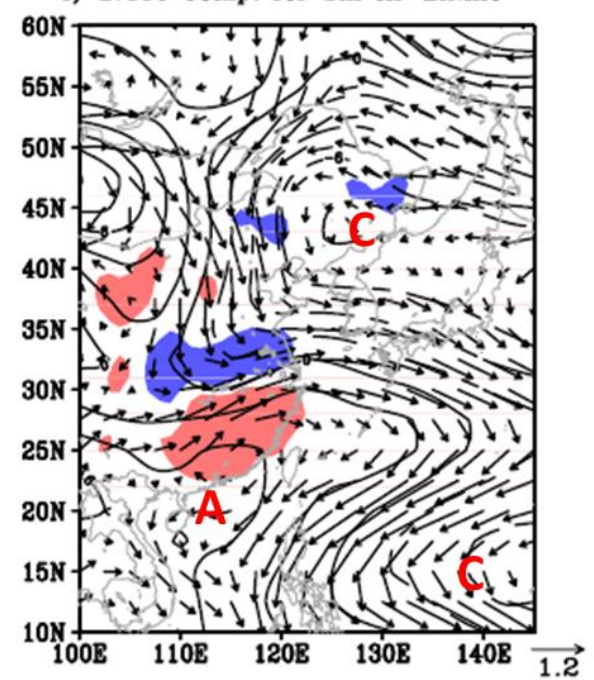

i) uv850 Comp. for Sm CP ElNino

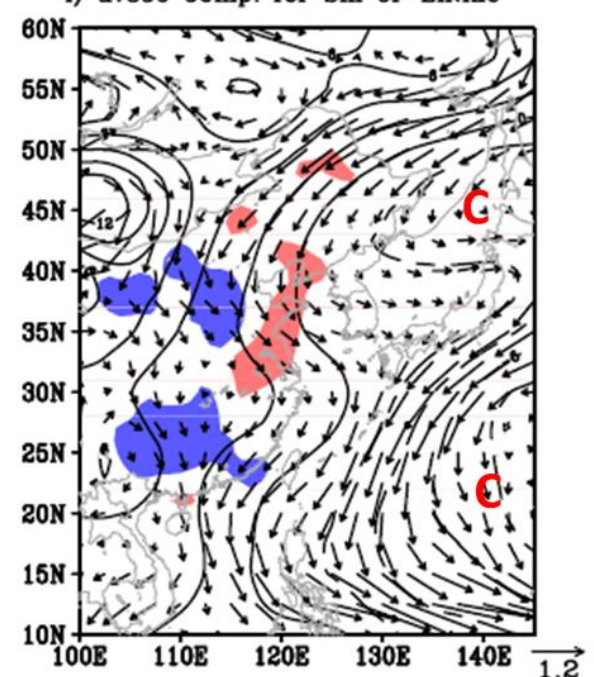

Figure 3 Composite atmospheric anomalies over East Asia, in association with the different types of summer El Niño. From top to bottom are summer EP, MP and CP El Niño respectively. Left panels (a, d and g) are $500 \mathrm{hPa}$ geopotential height (shaded, $\mathrm{CI}=6 \mathrm{~m}$ ) and wind anomaly (vector, unit: $\mathrm{m} / \mathrm{s}$ ), superimposed with the climatological air temperature at $850 \mathrm{hPa}$ (red contours, $\mathrm{CI}=2{ }^{\circ} \mathrm{C}$ ). In addition, the composite Western Pacific Subtropical high is also indicated by the $5860 \mathrm{~m}$ geopotential height line (the thick dark red 
dashed contour) with its climatological mean (the thick dark red solid contour). The thick black solid line segments mark the strengthened $500 \mathrm{hPa}$ troughs over East Asia. Middle panels (b, e and h) are $500 \mathrm{hPa}$ vertical velocity $(-\omega)$ anomalies (contours with solid/dash lines for positive/negative values, $\mathrm{CI}=0.3$ $\times 10^{-2} \mathrm{~Pa} / \mathrm{s}$ ). Right panels (c, f and i) are $850 \mathrm{hPa}$ geopotential height (black contours, $\mathrm{CI}=2 \mathrm{~m}$ ) and 850 $\mathrm{hPa}$ wind (vector, unit: $\mathrm{m} / \mathrm{s}$ ) anomalies, with red letters " $\mathrm{C}$ " and "A" marking cyclones and anticyclones respectively. The shadings in the middle and right panels indicate the corresponding precipitation anomalies, as in Fig. $2 b, d$ and $f$, with the blue (red) representing precipitation anomalies greater (less) than $+(-) 10 \%$. 
a) PREC Prec. Comp. for Sm EP El Nino (1958-2015)

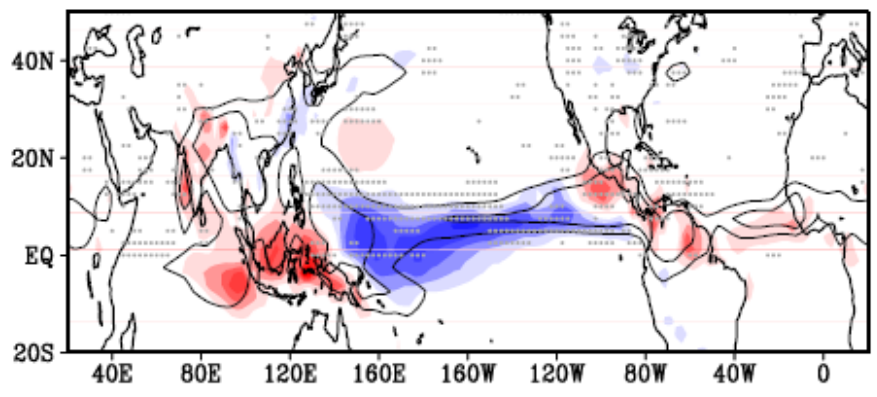

c) PREC Prec. Comp. for Sm MP El Nino (1958-2015)

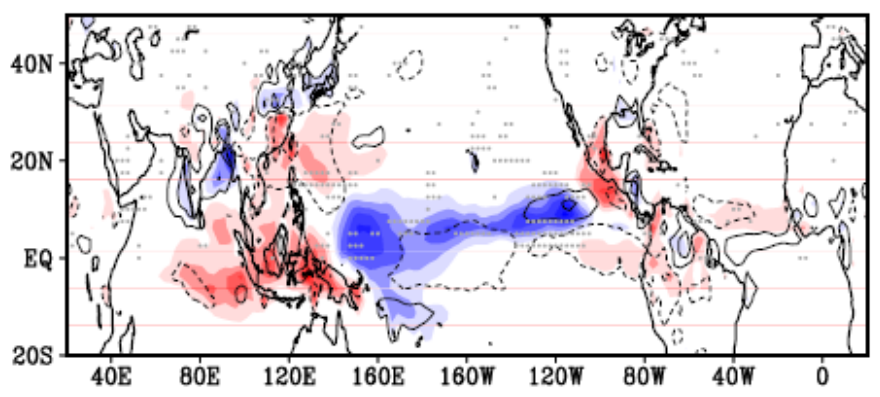

e) PREC Prec. Comp. for Sm CP El Nino (1958-2015)

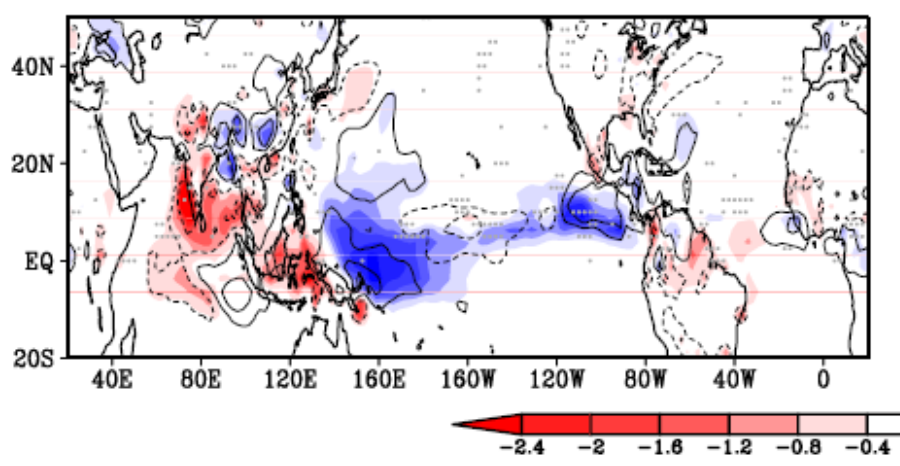

b) GPCP Prec. Comp. for Sm EP El NIno (1979-2015)

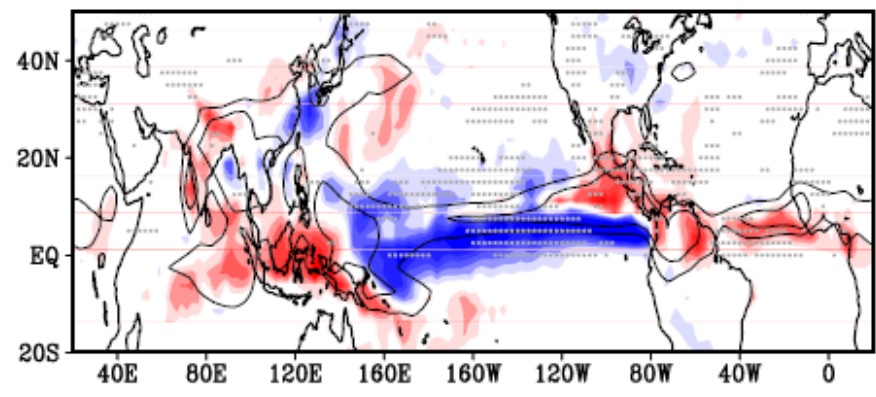

d) GPCP Prec. Comp. for Sm MP El Nino (1979-2015)

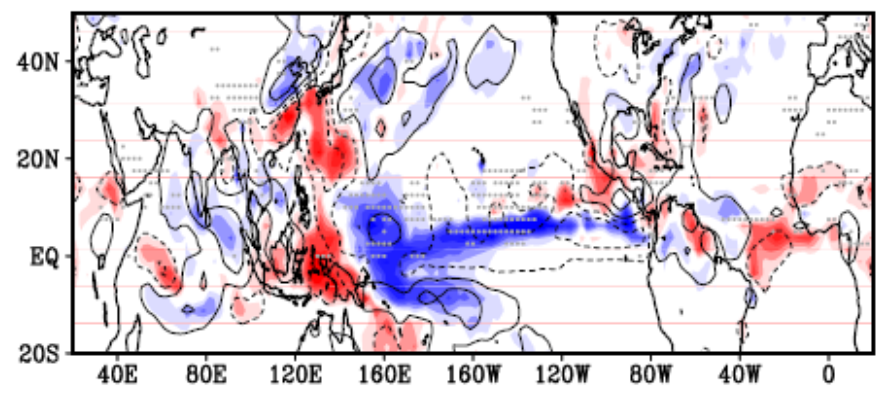

f) GPCP Prec. Comp. for Sm CP El Nino (1979-2015)

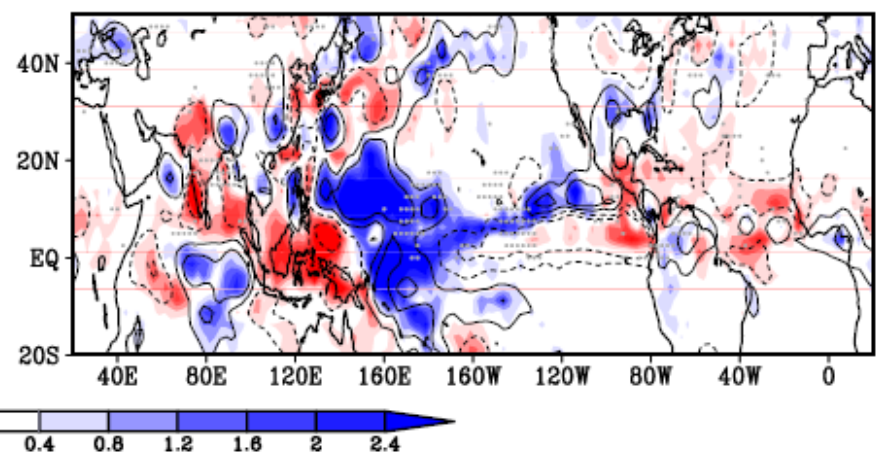

Figure 4 Composite precipitation anomalies (shaded) from two datasets, in association with the different types of summer El Niño. From top to bottom are summer EP, MP and CP El Niño respectively. Left panels (a, c and e) are PREC precipitation anomalies ( $\mathrm{CI}=0.4 \mathrm{~mm} /$ day) during the period of 1958-2015. Right panel (b, $d$ and f) are GPCP precipitation anomalies ( $\mathrm{CI}=0.5 \mathrm{~mm} /$ day) during the period of 1979-2015. In upper panels, the black contours indicate GPCP climatological precipitation from 1979 to 2015, with contour levels 5 and $8 \mathrm{~mm} /$ day. In middle (bottom) panels, the black contours indicate the difference of the precipitation of MP (CP) El Niño from that of EP El Niño. The gray dots denote the $90 \%$ confidence level. 
a) Walker Circulation for Sm EP El Nino

8

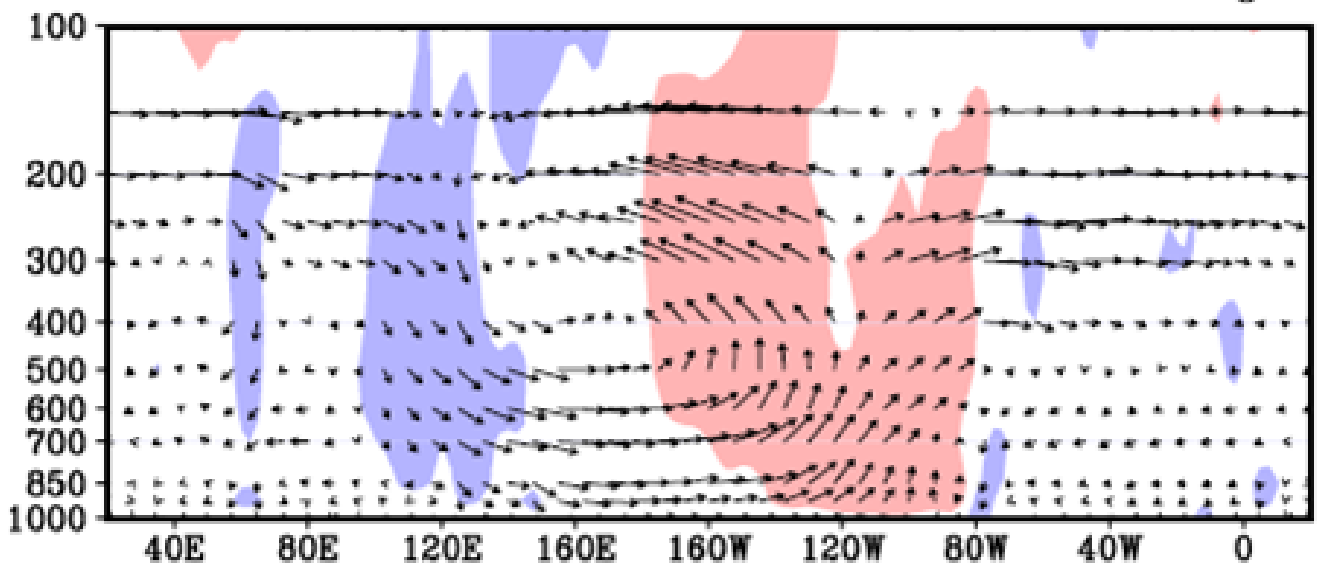

b) Walker Circulation for Sm MP E1 Nino
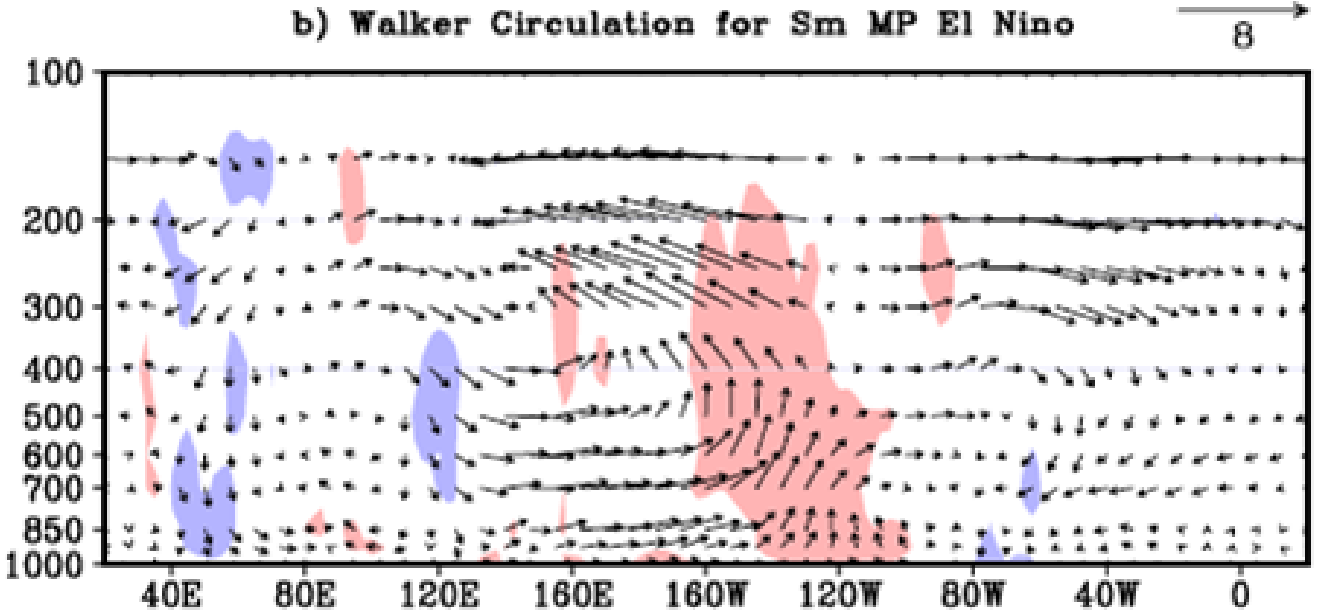

c) Walker Circulation for Sm CP E1 Nino

8

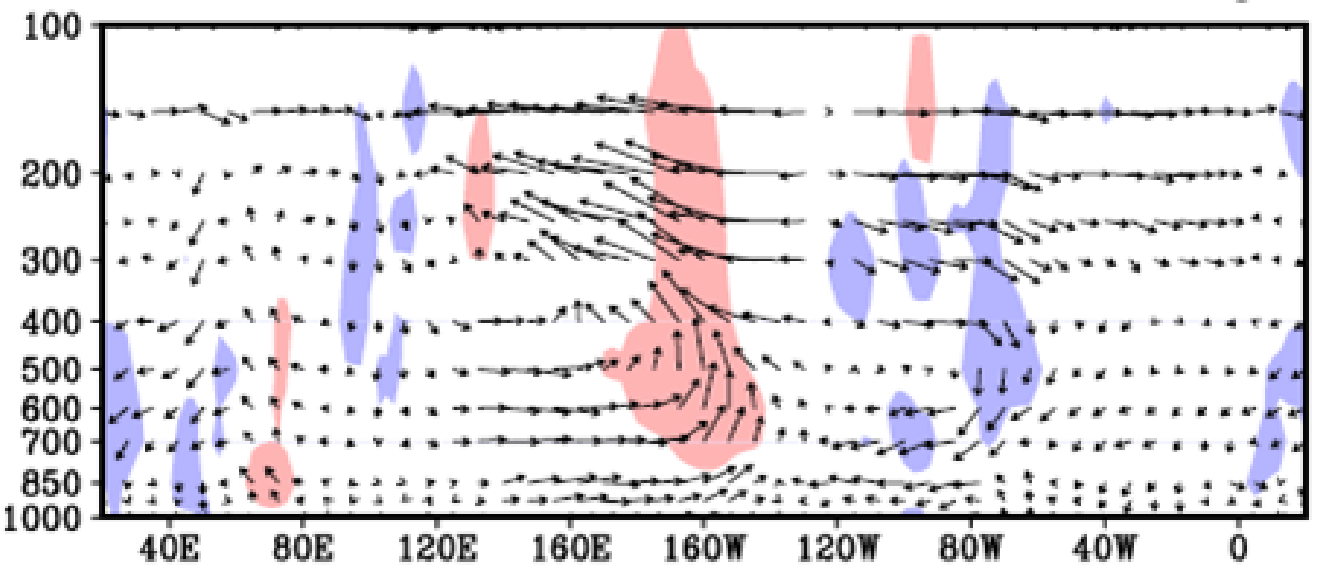

Figure 5 Composite Walker Circulation anomalies over the equator $\left(5^{\circ} \mathrm{S}-5^{\circ} \mathrm{N}\right)($ unit: $\mathrm{m} / \mathrm{s})$, in association with the different types of summer El Niño. The vertical velocities are magnified by 100 times. The upper, middle and bottom panels correspond to summer EP, MP and CP El Niño, respectively. The red/blue shadings indicate the $90 \%$ confidence level for air ascending and descending. 


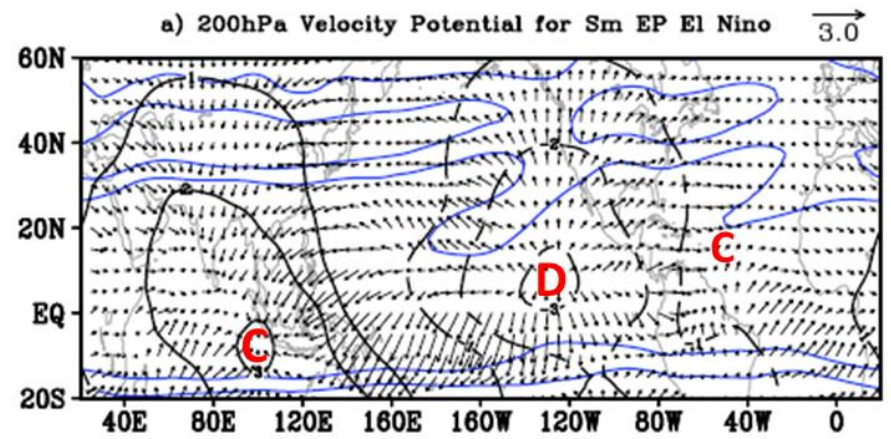

b) $850 \mathrm{hPa}$ Velocity Potential for Sm EP El Nino $\overrightarrow{1.5}$

c) $200 \mathrm{hPa}$ Velocity Potential for Sm MP El Nino $\overrightarrow{3.0}$
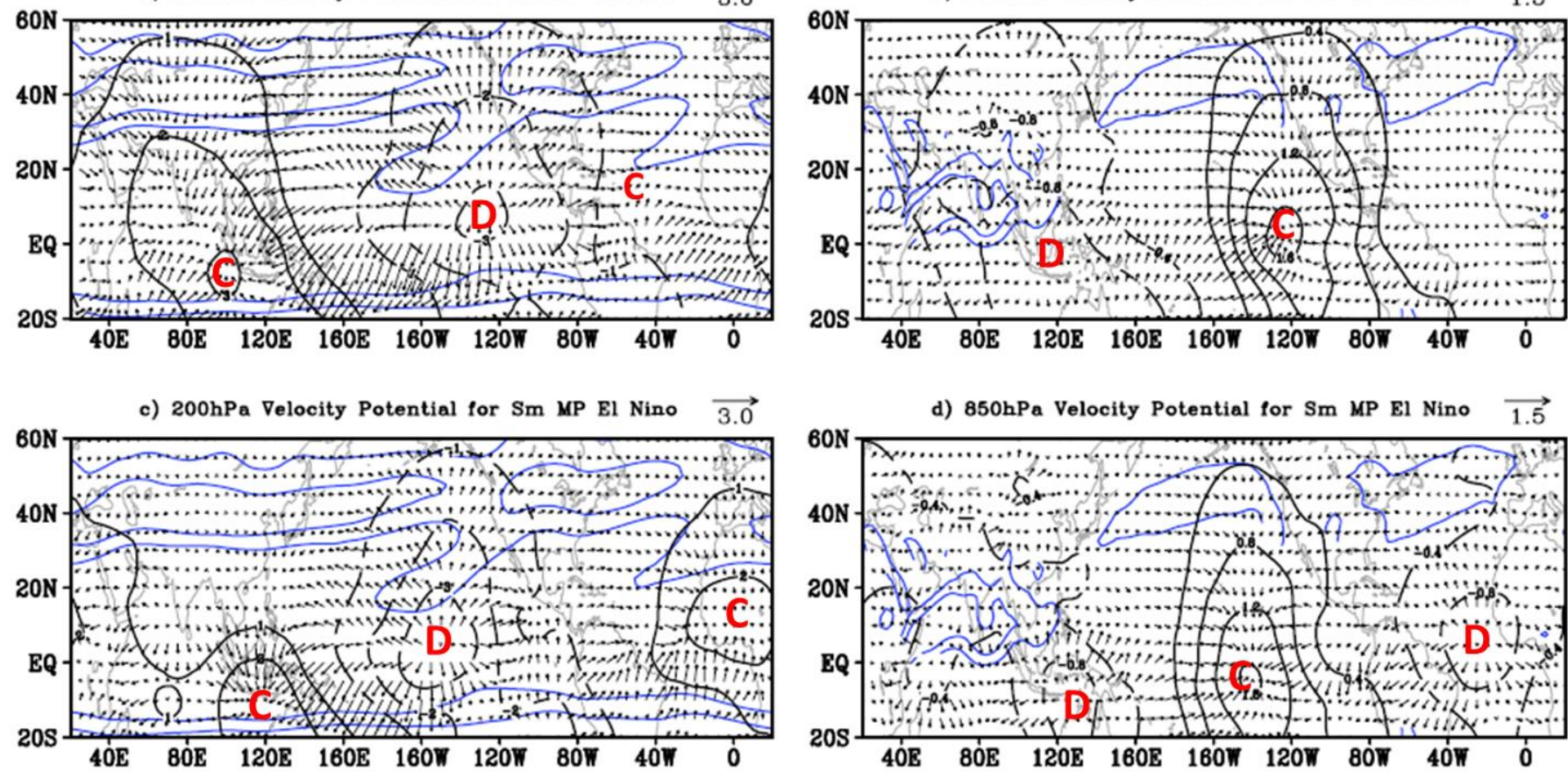

d) $850 \mathrm{hPa}$ Velocity Potential for Sm MP El Nino $\overrightarrow{1.5}$

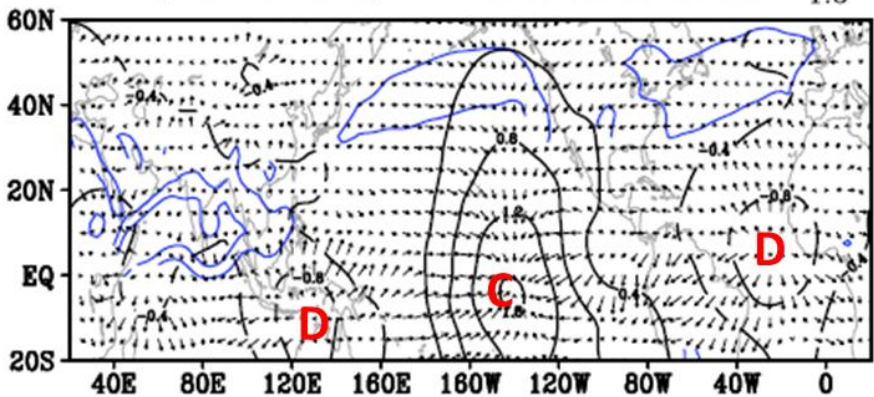

e) $200 \mathrm{hPa}$ Velocity Potential for Sm CP El Nino $\overrightarrow{3.0}$

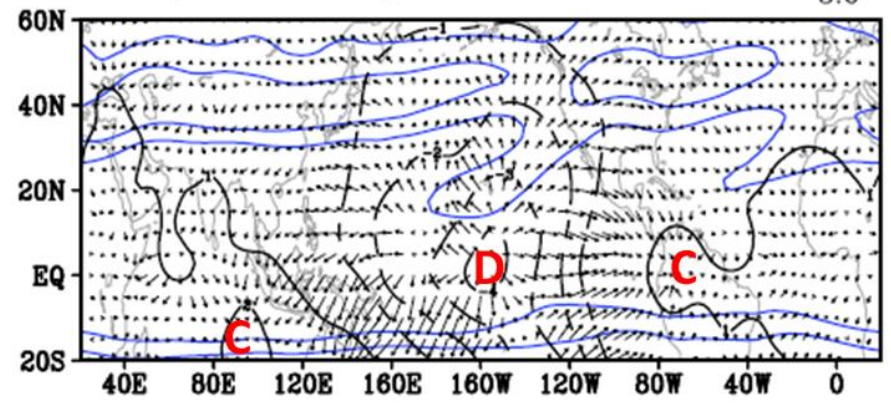

f) $850 \mathrm{hPa}$ Velocity Potential for Sm CP El Nino $\overrightarrow{1.5}$

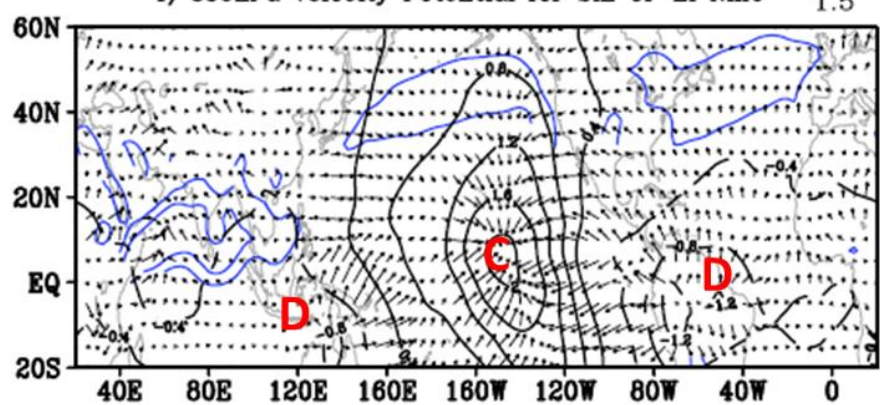

Figure 6 Composite anomalies of velocity potential (black contours, unit: $10^{6} \mathrm{~m}^{2} / \mathrm{s}$ ) and divergent wind (vector, unit: $\mathrm{m} / \mathrm{s}$ ) at $200 \mathrm{hPa}$ (left panel) and $850 \mathrm{hPa}$ (right panel), in association with the different types of summer El Niño. From top to bottom are summer EP, MP and CP El Niño respectively. Contour intervals of the velocity potentials are $1.0 \times 10^{6} \mathrm{~m}^{2} / \mathrm{s}$ at $200 \mathrm{hPa}$ and $0.4 \times 10^{6} \mathrm{~m}^{2} / \mathrm{s}$ at $850 \mathrm{hPa}$. The superimposed blue contours denote the climatological westerly winds with speed $10,20 \mathrm{~m} / \mathrm{s}$ at $200 \mathrm{hPa}$ (left panels) and 5,10 $\mathrm{m} / \mathrm{s}$ at $850 \mathrm{hPa}$ (right panels). The red letters " $\mathrm{C}$ " and " $\mathrm{D}$ " mark the convergence and divergence of the wind perturbation, respectively. 
a) 200hPa Wave Flux \& Vorticity for Sm EP El Nino

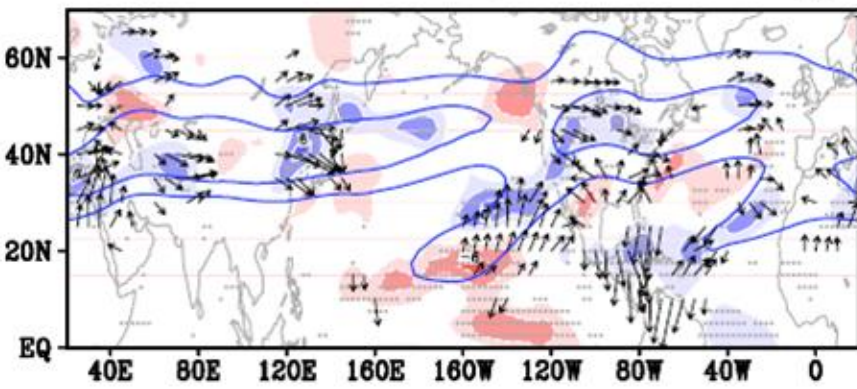

c) 200hPa Wave Flux \& Vorticity for Sm MP El Nino $\overrightarrow{1.2}$

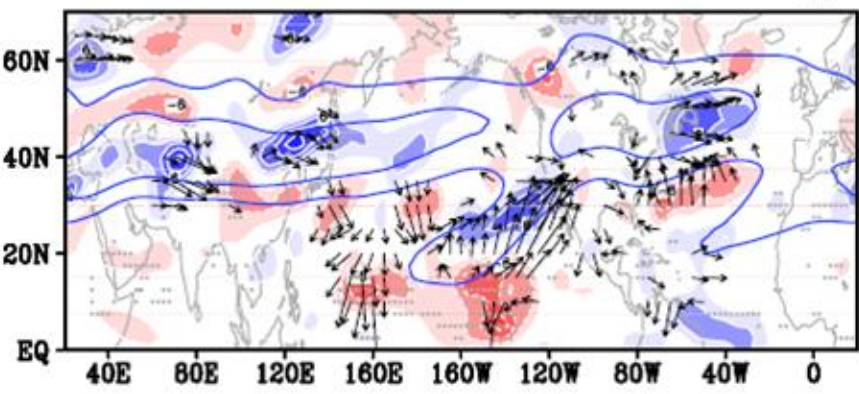

e) $200 \mathrm{hPa}$ Wave Flux \& Vorticity for Sm CP El Nino $\overrightarrow{1.2}$

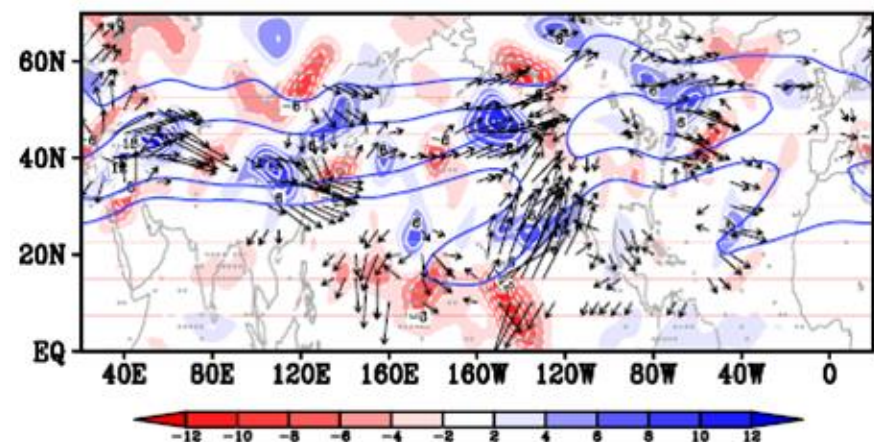

b) $850 \mathrm{hPa}$ Wave Flux \& Vorticity for Sm EP El Nino $\quad \overrightarrow{1.2}$

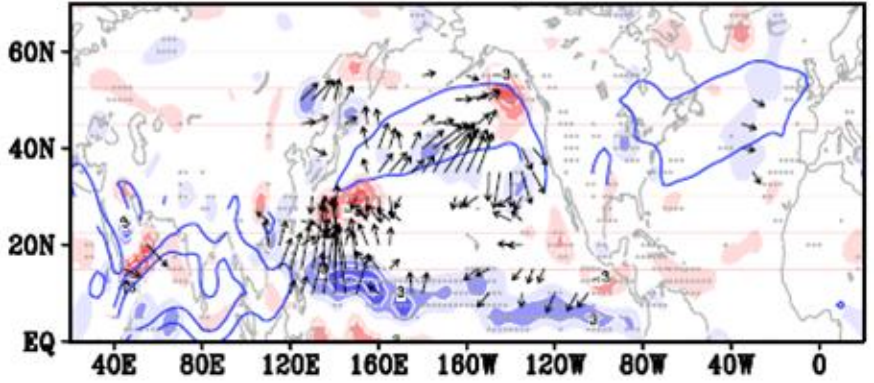

d) $850 \mathrm{hPa}$ Wave Flax \& vorticity for Sm MP El Nino $\overrightarrow{1.2}$

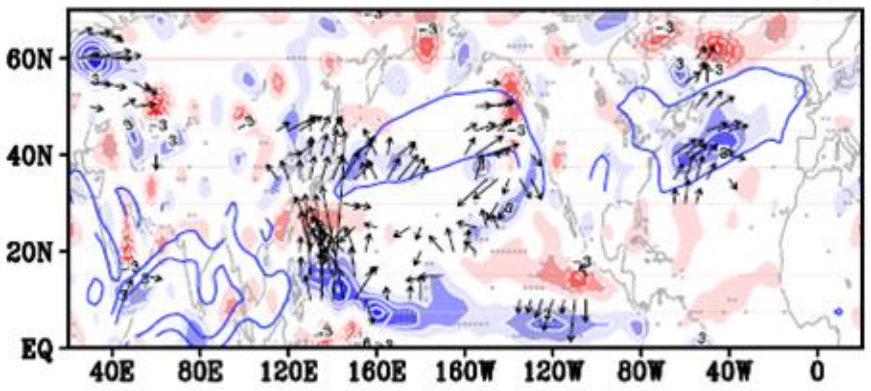

f) $850 \mathrm{hPa}$ Wave Flux \& Vorticity for Sm CP El Nino $\overrightarrow{1.2}$

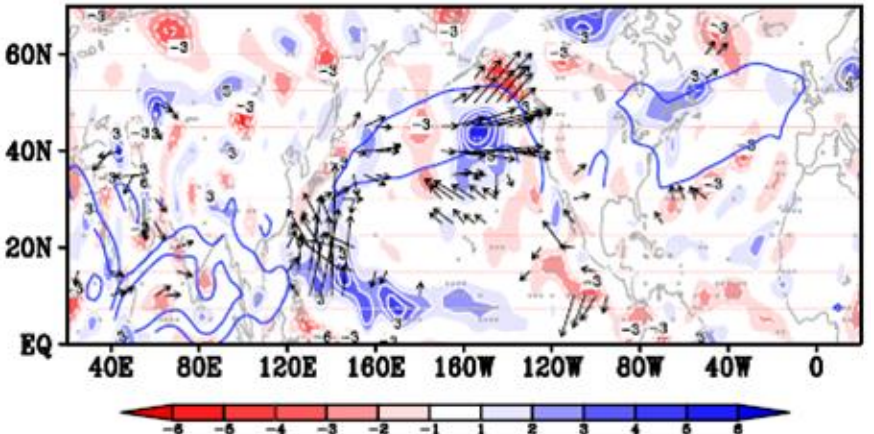

Figure 7 Composites of vorticity (shading, unit: $\mathrm{s}^{-1}$ ) and wave activity flux (vector, unit: $\mathrm{m}^{2} / \mathrm{s}^{2}$ ) at $200 \mathrm{hPa}$ (left panel) and $850 \mathrm{hPa}$ (right panel) in association with the different types of summer El Niño. From top to bottom are summer EP, MP and CP El Niño respectively. Contour intervals of the vorticity are $2 \times 10^{-6} \mathrm{~s}^{-1}$ at $200 \mathrm{hPa}$ and $1 \times 10^{-6} \mathrm{~s}^{-1}$ at $850 \mathrm{hPa}$. Small values of the wave activity flux with magnitude less than $0.2 \mathrm{~m}^{2} / \mathrm{s}^{2}$ are omitted. The superimposed blue contours denote the climatological westerly wind, with speed 10, 20 $\mathrm{m} / \mathrm{s}$ at $200 \mathrm{hPa}$ and $5,10 \mathrm{~m} / \mathrm{s}$ at $850 \mathrm{hPa}$. The gray dots indicate the $90 \%$ confidence level. 


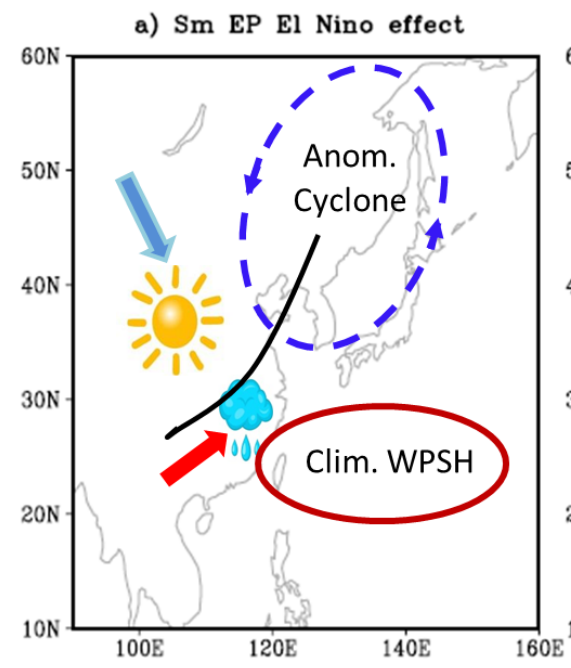

b) Sm MP El Nino effect

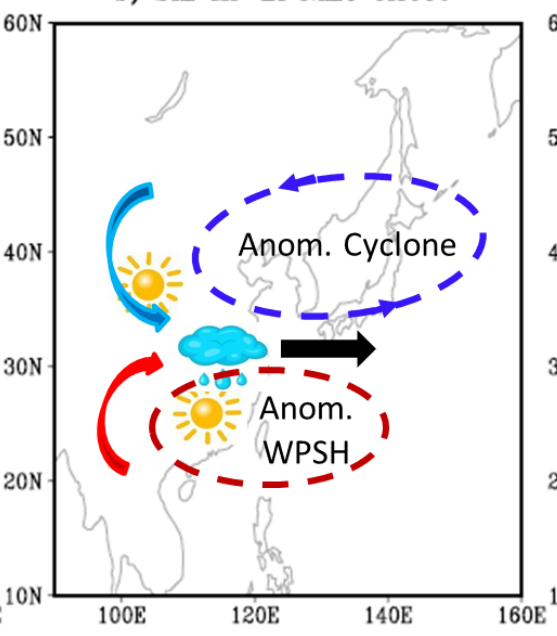

c) Sm CP El Nino effect

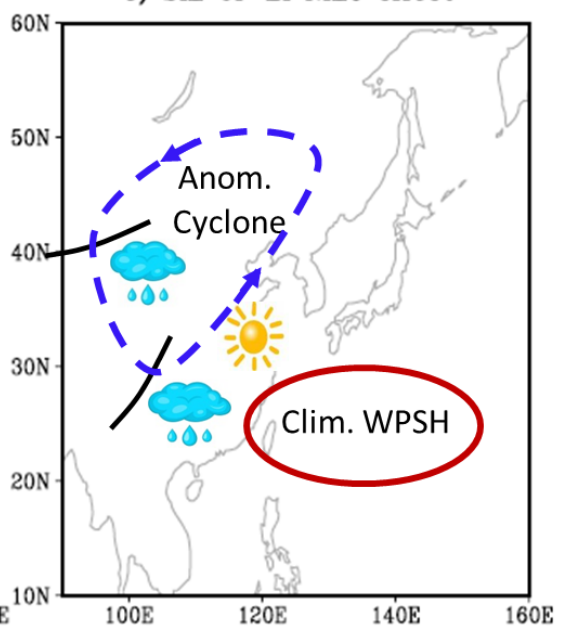

Figure 8 Schematic diagrams showing the impact of different types of El Niño in developing summer on East Asian summer precipitation. a) For summer EP El Niño, the dipole precipitation response with anomalous wetness in Southeast China and anomalous dryness in northern China is mainly due to the El Niño-induced low pressure anomaly over Northeast Asia, as indicated by the blue dashed circle. The dark red solid circle indicates the climatological mean of the West Pacific Subtropical High. b) For summer MP El Niño, the typical tripole precipitation anomaly with wet conditions along the Yangtze-Huaihe River valley and dry conditions in South and North China and is mainly due to the confrontational situation of the El Niño-induced low pressure anomaly over Northeast Asia (the blue dash circle) and the westward shift of the Western Pacific Subtropical High (the dark red dashed circle). c) For summer CP El Niño, the triangle-pattern precipitation anomaly with anomalous wetness in northern and southern China and anomalous dryness in the Jianghuai Region is mainly attributed to the abnormal cyclone occupying central-north East Asia (the blue dashed circle). The dark red solid circle indicates the climatological mean of the Western Pacific Subtropical High. The vectors in the sketch denote the wind direction with red and blue indicating warm and cold air respectively. 